\title{
Aerodynamic roughness variation with vegetation: analysis in a suburban neighbourhood and a city park
}

\author{
Christoph W. Kent ${ }^{1}$ (D) ${\text { Keunmin } \text { Lee }^{2} \text { (D) - Helen C. Ward }}^{1}$ (D) - Je-Woo Hong ${ }^{2}$ (D) \\ Jinkyu Hong ${ }^{2}$ (D) David Gatey ${ }^{3}$ D $\cdot$ Sue Grimmond $^{1}$ (D)
}

Published online: 27 November 2017

(C) The Author(s) 2017, corrected publication March/2018. This article is an open access publication

\begin{abstract}
Local aerodynamic roughness parameters (zeroplane displacement, $z_{d}$, and aerodynamic roughness length, $z_{0}$ ) are determined for an urban park and a suburban neighbourhood with a new morphometric parameterisation that includes vegetation. Inter-seasonal analysis at the urban park demonstrates $z_{d}$ determined with two anemometric methods is responsive to vegetation state and is $1-4 \mathrm{~m}$ greater during leaf-on periods. The seasonal change and directional variability in the magnitude of $z_{d}$ is reproduced by the morphometric methods, which also indicate $z_{0}$ can be more than halved during leaf-on periods. In the suburban neighbourhood during leaf-on, the anemometric and morphometric methods have similar directional variability for both $z_{d}$ and $z_{0}$. Wind speeds at approximately 3 times the average roughnesselement height are estimated most accurately when using a morphometric method which considers roughness-element height variability. Inclusion of vegetation in the morphometric parameterisation improves wind-speed estimation in all cases. Results indicate that the influence of both vegetation and roughness-element height variability are important for accurate determination of local aerodynamic parameters and the associated wind-speed estimates.
\end{abstract}

Christoph W. Kent

C.W.Kent@pgr.reading.ac.uk

Sue Grimmond

c.s.grimmond@reading.ac.uk

1 Department of Meteorology, University of Reading, Reading RG6 6BB, UK

2 Ecosystem-Atmosphere Process Laboratory, Department of Atmospheric Sciences, Yonsei University, Seoul 03722, Republic of Korea

3 Risk Management Solutions, London EC3R 8NB, UK
Keywords Anemometric methods $\cdot$ Aerodynamic roughness length $\cdot$ Morphometric methods $\cdot$ Source area $\cdot$ Vegetation . Wind $\cdot$ Zero-plane displacement

\section{Introduction}

The (dis)services of urban vegetation are both context and scale specific, therefore cannot be generalised (Salmond et al. 2016). However, as the socio-environmental and economic benefits of urban 'green spaces' are realised, they are increasingly becoming part of planning agendas to mitigate climate change, improve urban sustainability and improve human well-being (e.g. Gill et al. 2007; Landry and Chakraborty 2009; Roy et al. 2012; Andersson-Sköld et al. 2015; Kremer et al. 2015; Salmond et al. 2016; Ward and Grimmond 2017). Green spaces therefore will continue to be (a greater) part of the urban fabric. Despite this, when modelling the urban environment vegetation is often neglected to simplify the problem (e.g. references within Grimmond et al. 2010, 2011). It is imperative that the understanding of the physical implications of urban vegetation is improved across micro-, local-, and regional scales. This extends beyond urban parks and vegetation in street canyons - as the edges of cities are approached vegetation may become the most prominent roughness elements (e.g. Giometto et al. 2017, Kent et al. 2017a).

The presence of urban vegetation has implications for the storage and fluxes of scalar properties (e.g. heat, moisture and pollutants). For example, vegetation can reduce the mean and extreme ambient and indoor temperatures (Smith et al. 2011, Schubert et al. 2012, Mavrogianni et al. 2014, Heaviside et al. 2015), whilst also reducing night-time longwave cooling (Coutts et al. 2016). Its presence tends to increase humidity (through increasing evapotranspiration) and is also responsible for precipitation interception, a reduction of run-off and 
increased soil water storage/ permeability (Stovin et al. 2008, Day et al. 2010, Vico et al. 2014). Vegetation contributes to pollutant absorption and deposition (Tiwary et al. 2009, Tallis et al. 2011, Salmond et al. 2016).

Vegetation influences the momentum flux by exerting drag on the mean wind flow (Finnigan 2000, Guan et al. 2003, Krayenhoff et al. 2015, Giometto et al. 2017). At critical aerodynamic porosities $\left(P_{3 D}\right)$ this drag can be as significant as solid structures of the same shape (Hagen and Skidmore 1971, Mayhead 1973, Grant and Nickling 1998, Guan et al. 2000, 2003, Rudnicki et al. 2004, Vollsinger et al. 2005, Koizumi et al. 2010, Kent et al. 2017a). Vegetation therefore influences the spatially-averaged mean and turbulent characteristics of the flow in urban areas (Krayenhoff et al. 2015), having implications for in-canopy flow (Salmond et al. 2013), as well as the exchange between in- and above-canopy air masses (Gromke and Ruck 2009, Vos et al. 2013).

The influence of a defined surface area upon fluxes of momentum can be indicated using the aerodynamic parameters of the zero-plane displacement $\left(z_{d}\right)$ and aerodynamic roughness length $\left(z_{0}\right)$, which are directly related to surface characteristics. Several methods exist to determine these, including algorithms based upon surface form (morphometric methods) or observations (anemometric methods). The presence of all roughness elements is inherently included in anemometric methods, but until recently morphometric methods did not consider both vegetation and buildings in combination. However, Kent et al. (2017a) develop the widely-used Macdonald et al. (1998) (hereafter Mac) morphometric method to include vegetation, which also applies to the Kanda et al. (2013) (Kan) extension of the Mac method.

The objectives of this paper are to use observations at two vegetated urban sites to investigate: (i) the seasonal variability in $z_{d}$ and $z_{0}$ with the seasonal change of tree phenology, (ii) Kent et al.'s (2017a) parameterisation of vegetation in the morphometric methods and (iii) the implications of considering vegetation for accurate wind-speed estimation. The interdependence of $z_{d}$ and $z_{0}$ means that a single value for each parameter cannot be treated as the 'truth'. Therefore, the analysis provides a comparison between the magnitude and directional variability of roughness parameters determined from the different methods. The wind-speed estimation application provides an independent assessment of the method performance.

\section{Methodology}

\section{Site description and observations}

Measurements from an urban park in Seoul, South Korea (Seoul Forest Park, SFP) and a suburban residential neighbourhood in Swindon, UK (SWD) are used. The obvious contrast of landscape with vegetation phenology means trees and other vegetation are expected to influence the aerodynamic properties of both areas, especially during leaf-on conditions when foliage is at relative maxima. Seoul Forest Park is the third largest park in Seoul ( 116 ha), with a dominance of vegetation evident (Fig. 1a-d). The SWD site is typical of UK suburbia, with a slightly larger proportion of buildings than vegetation, but this varies with direction (e.g. Fig. 1e, f). Considerable research at the SWD site means anthropogenic and biogenic controls of energy, water and carbon fluxes and their temporal variability are well understood (Ward et al. 2013, 2014, 2015a, 2015b, 2015c). In addition, the site has been used during development of the Surface Urban Energy and Water Balance Scheme (SUEWS) (Ward et al. 2016). However, in-depth aerodynamic parameter analysis has not been performed at either the SFP or SWD site.

At each site, fast-response observations of temperature, wind velocity $(u$ - horizontal, $v$ - transverse and $w$ - vertical components), $\mathrm{CO}_{2}$ and $\mathrm{H}_{2} \mathrm{O}$ are processed into 30-min averages (Table 1).

\section{Surface elevation database and differentiation between buildings and vegetation}

At both sites, 1-m horizontal resolution digital surface (DSM, ground height + surface features) and digital terrain (DTM, ground height only) models are analysed (Table 2). The high resolution and accuracy of these data, allow intricacies of surface roughness (e.g. roof pitch) to be resolved. After subtraction of the DTM from the DSM to provide a roughness element surface model (RESM), pixels $<2 \mathrm{~m}$ high are removed (i.e. street furniture and temporary obstacles, such as vehicles). This retains roughness elements which are most appropriate for application of the morphometric methods. Building and vegetation pixels are differentiated by three techniques.

For the SFP site, initial source area calculations (using the Kormann and Meixner (2001) and Kljun et al. (2015) models) indicate the measurements are consistently influenced by an area within $300 \mathrm{~m}$ of the sensor. The area within this radius is classified using a manual and automated technique. The manual technique entails classification of aerial photography (Fig. 2a) into: building, road, impervious, water, forest, grass, bare soil and other (unclassified, but with few roughness elements) (Fig. 2b), with the RESM data overlain to check for inconsistencies. This manual method has some limitations, for example, although buildings (predominantly rectangular with sharp boarders) are mostly captured, those within a waterworks (south of the SFP site) and in a ready mixed concrete (RMC) factory (north-west) are misclassified (Fig. 2b). Additionally, considerable vegetation is missed, especially at land cover interfaces (e.g. along roadsides and bare soil paths, Fig. $2 \mathrm{~b}$ and c, magenta circles). After re-classification, a surface model of building (BSM) and vegetation canopy (CDSM) heights is created (Fig. 2c). 
Fig. 1 View from the: (a-d) Seoul Forest Park (SFP) and (e-f) Swindon (SWD) measurement locations, with approximate directions

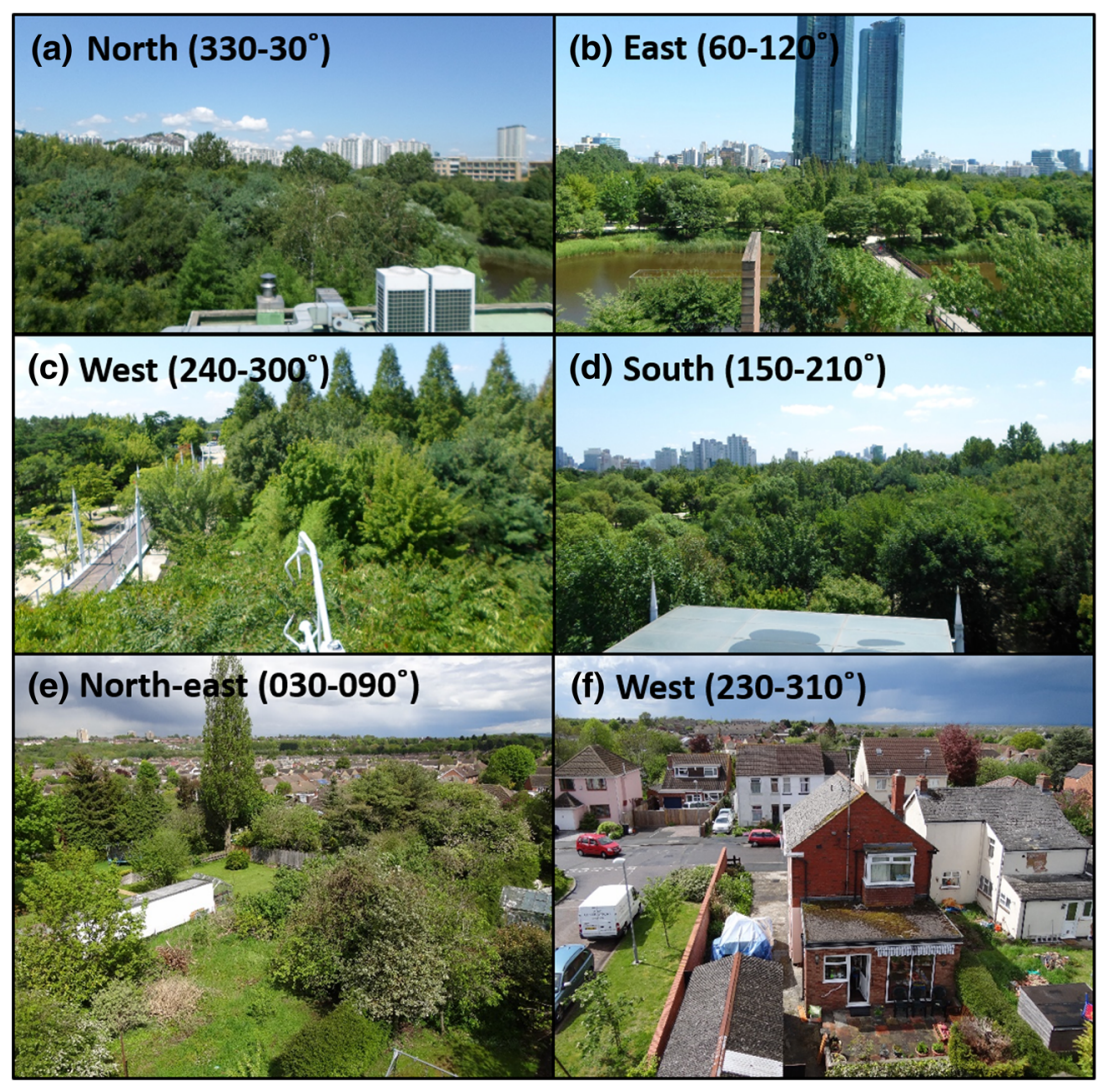

The automated separation of buildings and vegetation, uses the RGB colour band of aerial imagery, as vegetation tends to be darker (i.e. lower end of the saturation spectrum) for all colour bands. If higher saturation pixels are removed, a binary mask representing pixels which are likely vegetation can be retained (e.g. Fig. 2d) (Crawford et al. 2016). Clouds in the imagery

Table 1 Site observation meta-data. Heights are metres above ground level

\begin{tabular}{|c|c|c|c|c|c|}
\hline $\begin{array}{l}\text { Site: Lat, Lon } \\
\text { (WGS84) }\end{array}$ & Local climate zone $(\mathrm{LCZ})^{*}$ & $\begin{array}{l}\text { Observation } \\
\text { period }\end{array}$ & $\begin{array}{l}\text { Measurement } \\
\text { height. Mounting. }\end{array}$ & Instrumentation & Data processing \\
\hline $\begin{array}{l}\text { Seoul Forest } \\
\text { Park (SFP) } \\
37^{\circ} 32^{\prime} 40.7^{\prime \prime} \\
\text { N } 127^{\circ} 2^{\prime} \\
16.4^{\prime \prime} \mathrm{E}\end{array}$ & $\begin{array}{l}\text { Scattered trees (type B): } \\
\text { predominantly mixed } \\
\text { forest (Pine, Ginkgo, } \\
\text { Zelkova trees), pond and } \\
\text { turf grass. Becoming } \\
\text { dense trees (type A) } \\
\text { within } 300 \text { m radius. }\end{array}$ & $\begin{array}{l}31 \text { May 2013-3 } \\
\text { June } 2015\end{array}$ & $\begin{array}{l}12.2 \mathrm{~m} . \\
230^{\circ} \text { orientation } \\
\text { on } 3.8 \mathrm{~m} \text { tripod } \\
\text { atop of } 8.4 \mathrm{~m} \\
\text { duplex } \\
\text { building. }\end{array}$ & $\begin{array}{l}\text { CSAT3 Sonic Anemometer; } \\
\text { EC155 closed-path gas } \\
\text { analyser } \\
\text { (Campbell Scientific, USA) }\end{array}$ & $\begin{array}{l}\text { Raw } 10 \mathrm{~Hz} \text { data processed to } \\
\text { 30-min averages with spike } \\
\text { detection (Papale et al. } \\
\text { 2006; Hong et al. 2009), } \\
\text { night-time correction } \\
\text { (Aubinet et al. 2000) and } \\
\text { double rotation of the wind } \\
\text { components, aligning the } \\
\text { wind field to the } u \text { direction } \\
\text { (McMillen 1988, Kaimal } \\
\text { and Finnigan 1994). }\end{array}$ \\
\hline $\begin{array}{l}\text { Swindon } \\
\qquad \begin{array}{l}\text { (SWD) } 51^{\circ} \\
35^{\prime} 4.6^{\prime \prime} \mathrm{N} 1^{\circ} \\
47^{\prime} 53.2^{\prime \prime} \mathrm{W}\end{array}\end{array}$ & $\begin{array}{l}\text { Open low-rise: well-spaced } \\
\text { low-rise residential } \\
\text { buildings and abundant } \\
\text { pervious land cover }\end{array}$ & $\begin{array}{l}9 \text { May 2011-30 } \\
\text { April 2013 }\end{array}$ & $\begin{array}{l}12.5 \mathrm{~m} . \\
\text { Pneumatic } \\
\text { mast. }\end{array}$ & $\begin{array}{l}\text { R3 Sonic Anemometer (Gill } \\
\text { Instruments, Lymington, } \\
\text { UK); LI-7500 open-path } \\
\text { gas analyser } \\
\text { (LI-COR Biosciences, } \\
\text { Lincoln, USA) }\end{array}$ & $\begin{array}{l}\text { Raw } 20 \mathrm{~Hz} \text { data processed to } \\
\text { 30-min averages using } \\
\text { EddyPro Advanced (v5-00, } \\
\text { LI-COR), which includes } \\
\text { de-spiking, double coordi- } \\
\text { nate rotation, humidity cor- } \\
\text { rection of sonic temperature } \\
\text { and high- and } \\
\text { low-frequency spectral cor- } \\
\text { rections (Moncrieff et al. } \\
\text { 1997). }\end{array}$ \\
\hline
\end{tabular}

*(Stewart and Oke 2012) 
Table 2 Source and accuracy of surface elevation databases used at the Seoul Forest Park (SFP) and Swindon (SWD) measurement sites

\begin{tabular}{lccl}
\hline Site & Elevation data source & $\begin{array}{l}\text { Horizontal } \\
\text { resolution }(\mathrm{m})\end{array}$ & $\begin{array}{l}\text { Accuracy: } \\
\text { horizontal, vertical } \\
(\mathrm{m})\end{array}$ \\
\hline SFP & $\begin{array}{c}\text { National Geographic } \\
\text { Information Institute }\end{array}$ & 1 & $0.15,0.10$ \\
SWD & $\begin{array}{c}\text { Environment agency } \\
\text { (UK) data archive }\end{array}$ & 1 & $0.40,0.15$ \\
\hline
\end{tabular}

causes some vegetation to be uncaptured by the mask (cf. Fig. 2a and e, magenta circle). A dark to lighter pixel transition on the edge of vegetation means the mask may be smaller than vegetation's true extent. Therefore, the binary mask and RESM are combined and a filtering algorithm flags pixels as vegetation if they are within $\pm 3 \mathrm{~m}$ of another pixel in the binary mask. Pixels not flagged are either buildings or other urban furniture (e.g. cars, street lamps etc.). After removing pixel heights $<2 \mathrm{~m}$, a final CDSM and BSM product is generated (Fig. 2e).

Although the manual (after re-classification) and automated CDSM and BSM products are almost identical (cf. Fig. 2c and e), the latter method is more practical. The remainder of this work uses a combined dataset from both procedures.

At the SWD site, the abundance of vegetation and proximity of built structures makes accurate manual classification difficult. Additionally, the automated technique frequently misclassifies building pixels as vegetation because of the dark roofs and excessive shading (e.g. Fig. 2f). Therefore, a building footprint dataset (OS MasterMap® Topography Layer - Building Height Attribute, Ordnance Survey 2014) (Fig. 2g) was overlain upon the RESM to create the BSM (Fig. $2 \mathrm{~h}$, red). The remaining pixels were classed as 'potential' vegetation pixels, with isolated pixels removed if fewer than 6 of the 8 surrounding pixels were not 'potential' vegetation (Goodwin et al. 2009, Lindberg and Grimmond 2011). The remaining pixels were stored as a CDSM (Fig. 2h, green).

\section{Calculation of aerodynamic roughness parameters}

Two anemometric methods are used to determine $z_{d}$ : the temperature variance (TVM, Rotach 1994) and wind variance (WVM, Toda and Sugita 2003) methods. The TVM and WVM are based upon the relation between the nondimensional standard deviation of temperature or vertical wind and stability parameter in the surface layer, during unstable conditions (Wyngaard et al. 1971, Tillman 1972):

$$
\begin{aligned}
& \phi_{T}=\frac{\sigma_{T}}{T_{*}}=-C_{1}\left(C_{2}-\frac{z^{-} z_{d}}{L}\right)^{-\frac{1}{3}} \\
& \phi_{w}=\frac{\sigma_{w}}{u_{*}}=C_{3}\left(1-C_{4}\left[\frac{z-z_{d}}{L}\right]\right)^{\frac{1}{3}}
\end{aligned}
$$

where $\sigma_{T}$ and $\sigma_{w}$ are the standard deviation of temperature and vertical wind velocity respectively, $T_{*}$ is the temperature scale, $T *=-\left(\overline{w^{\prime} T^{\prime}}\right) / u_{*}$ (with $T$ the temperature, $w$ the vertical wind velocity, $u_{*}$ friction velocity, the overbar representing a mean value and prime indicating deviation from the mean), $L$ is the Obukhov length, $L=\frac{\bar{T} u *^{2}}{k g T *}$ (with $g$ the gravitational acceleration and $\kappa$ von Karman's constant $=0.4$, Högström 1996) and $C_{1}-C_{4}$ are constants.

The TVM and WVM are amongst the few methods that permit roughness parameters to be derived from single-level turbulence measurements. However, the methods rely on Monin-Obukhov similarity theory and that the resulting flux gradient relations used by the TVM and WVM (Eq. 1 and 2) apply in urban areas (see Roth and Oke 1995). Therefore, the applicability of the similarity relations used by the methods is assessed at both sites during this work. Although the similarity relations are expected to hold where flow is free from roughness-element wakes (i.e. within the inertial sublayer), the TVM is specifically developed to determine $z_{d}$ from measurement locations which may be distorted by local roughness-element wakes (i.e. within the roughness sublayer) (Rotach 1994). Previous analysis indicates results from the WVM are appropriate in similar heterogeneous locations (Toda and Sugita 2003, Kent et al. 2017b).

The constants $\left(C_{I}\right.$ to $\left.C_{4}\right)$ are derived from observations when $z_{d}$ is assumed negligible. Although the constants vary (e.g. Sorbjan 1989, Hsieh et al. 1996, Choi et al. 2004), the $z_{d}$ from the temperature and wind variance methods was found to be relatively insensitive to the range in a dense urban area (Kent et al. 2017b). To assess the effect of constant choice on the final solution to $z_{d}$ the methods are applied with a range of constants (Table 3). Note, if constants are fit to the observations at a site an $a$ priori assumption of $z_{d}$ is required and therefore the $z_{d}$ retrieved is not useful (Kent et al. 2017b).

The right-hand sides of Eq. 1 and 2 are estimated by increasing $z_{d}$ from zero to twice the measurement height $\left(z_{m}\right)$ in $0.1 \mathrm{~m}$ increments (producing $\left.\phi_{e s t}\right)$. The $z_{d}$ is the value which minimises the root-mean-square error (RMSE) between $\phi_{\text {est }}$ and the observed value $\left(\phi_{o b s}\right)$ of $\sigma_{T} / T_{*}$ or $\sigma_{w} / u_{*}$ (for the TVM and WVM, respectively). As calculations are undertaken for unstable conditions $\left(0.05 \leq-z^{\prime} / L \leq 6.2\right.$, Roth $\left.2000 ; z^{\prime}=z_{m}-z_{d}\right)$ an initial $z_{d}$ for stability definition is required. Thus, the methods are applied to $10^{\circ}$ wind sectors around the sites with: (i) the $z_{d}$ for stability definition varied from 0 to $10 \mathrm{~m}$ in 2 $\mathrm{m}$ increments (a larger initial $z_{d}$ provides insufficient data to apply the methods); and (ii) different constants (i.e. Table 3).

If measurements are free from roughness-element wakes (i.e. within the inertial sublayer), the 'eddy-covariance (EC) 


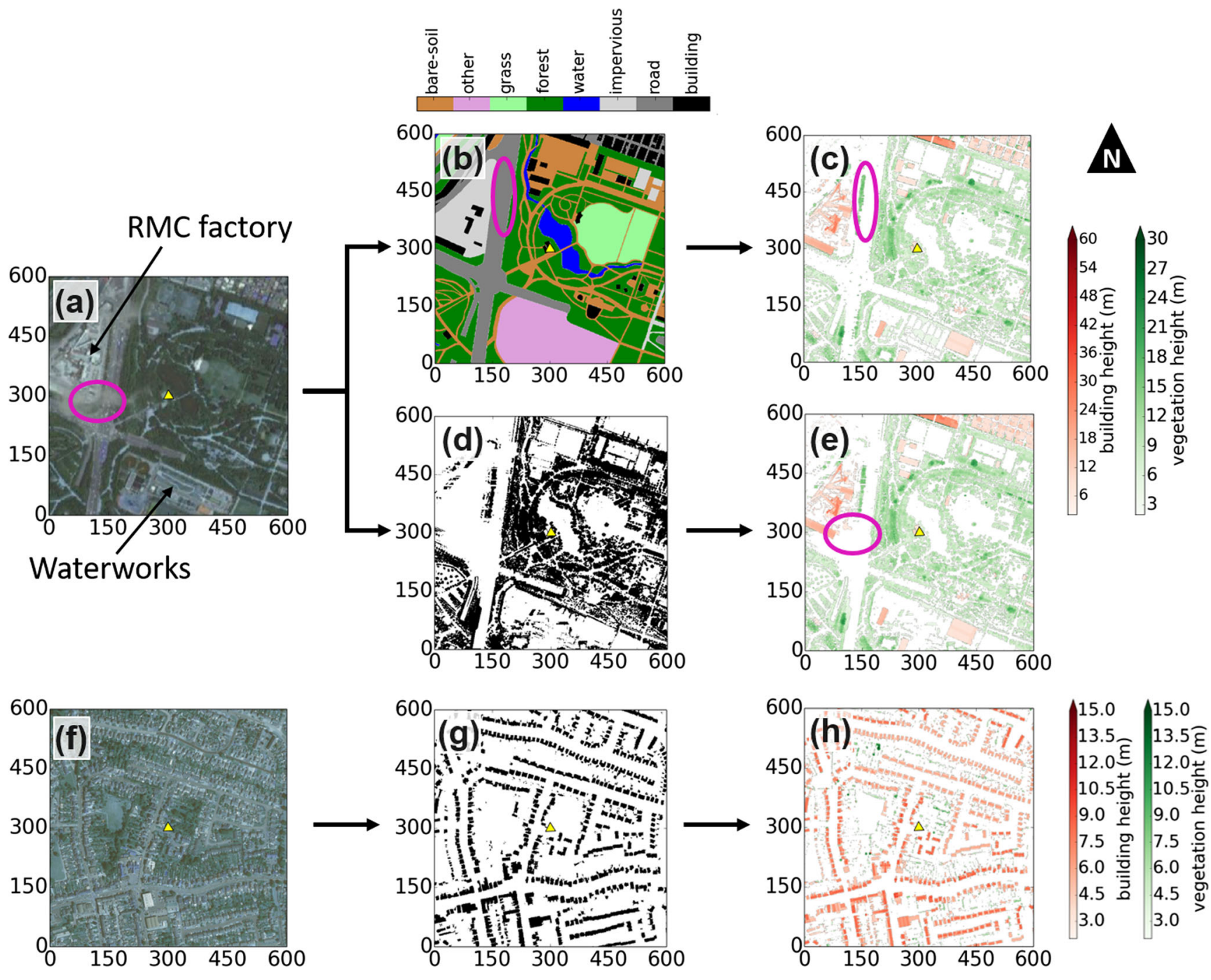

Fig. 2 Classification of buildings and vegetation for the (a-e) Seoul Forest Park and (f-h) Swindon site (yellow triangles) surroundings: (a, f) aerial photograph; (b) manual land cover classification; (c) building digital surface model (BSM, red) and canopy digital surface model (CDSM, green) from manual technique; (d) vegetation mask from analysis of RGB colour bands in (a); (e) BSM and CDSM from

automated technique; (g) building footprints; and, (h) BSM and CDSM using building footprint mask. Magenta circles are referred to in text. Map units are metres. Data sources: aerial imagery - Seoul city aerial image service centre, Digimap 2017; elevation data - see Table 2; building footprints - Ordnance Survey 2014

method' can be used to determine $z_{0}$, which is a rearrangement of the logarithmic wind law:

$z_{0}=\left(z^{-} z_{d}\right) \exp \left(-\frac{\bar{U}_{z} \kappa}{u *}\right)$

where the average wind speed $\left(\bar{U}_{z}\right)$ and $u_{*}$ are determined from observations at $z_{m}$. For each 30-min period of observations, $z_{d}$ from both the temperature and wind variance methods are used, providing two $z_{0}$ solutions. The EC method, applicable under neutral conditions $\left(\left|z^{\prime} / L\right| \leq 0.05\right)$, requires at least 20 observations to determine $z_{0}$ for a directional sector (Beljaars 1987, Grimmond et al. 1998). Additionally, only $\bar{U}_{z}$
$>1 \mathrm{~m} \mathrm{~s}^{-1}$ are analysed to ensure sufficient mechanical turbulence (Liu et al. 2009). Stability corrections may be used to apply the EC method outside of neutral conditions. However, these corrections are based upon empirical fits to observed data and vary across studies (Högström 1996). To avoid additional sources of uncertainty only neutral conditions are considered here.

As the SFP site results indicate $z_{d}$ is similar to (or greater than) $z_{m}$, the EC method to determine $z_{0}$ is therefore unusable (and not applied). For both northern-hemisphere sites, leaf-off periods are selected as the (core) winter months of December, January and February; and leaf-on periods are June, July and August. With little solar radiation during winter (leaf-off periods) at the SWD site there are insufficient unstable periods 
to determine $z_{d}$ using the temperature and wind variance methods (and hence $z_{0}$ ). Therefore, only leaf-on conditions are analysed at the SWD site.

The Macdonald et al. (1998, Mac) and Kanda et al. (2013, Kan) morphometric methods are used with a new vegetation parameterisation (Kent et al. 2017a). Following the Kent et al. (2017b) methodology, an iterative procedure is applied using the Kormann and Meixner (2001) footprint model with 30-min averaged meteorological observations. Initial rural $z_{d}$ and $z_{0}$ values $(0.2$ and $0.03 \mathrm{~m}$, respectively) are used, as results are independent of these values when applying an iterative procedure (Kent et al. 2017b). Morphometric calculations are only applied to source areas which extend horizontally beyond $50 \mathrm{~m}$ from the measurement sensors, as smaller source areas become concentrated upon only a few roughness elements and the morphometric calculations are inappropriate.

For each 30-min observation, the source area weighted geometry is calculated for buildings and vegetation (using the BSM and CDSM). The average, maximum and standard deviation of all roughness-element heights $\left(H_{a v} H_{\max }\right.$ and $\sigma_{H}$, respectively) are determined. The plan area index $\left(\lambda_{p}\right)$ of roughness elements is:

$\lambda_{p}=\frac{W_{p, b}+W_{p, v}\left(1-P_{3 D}\right)}{W_{A T}}$

where $W_{p, b}$ and $W_{p, v}$ are the sums of weighted pixels in the source area of buildings and vegetation, respectively, $W_{A T}$ is

Table 3 Constants $\left(C_{1}-C_{4}\right)$ for application of the temperature variance (TVM) and wind variance (WVM) anemometric methods (Eq. 1 and 2). For all observations, extensive flat homogeneous terrain is reported. Kaimal and Finnigan (1994) and Toda and Sugita (2003) are after synthesis of coefficients from various studies. At the SWD site, the Choi et al. (2004) constants are not applied, as they predict the scaled $\sigma_{T}$ and $\sigma_{w}$ to be much larger and smaller than observations, respectively, meaning $z_{d}$ solutions are consistently zero

\begin{tabular}{lcccccc}
\hline Reference & \multicolumn{2}{c}{ TVM } & & & \multicolumn{2}{l}{ WVM } \\
\cline { 2 - 3 } \cline { 7 - 7 } & $C_{1}$ & $C_{2}$ & & $C_{3}$ & $C_{4}$ \\
\hline Tillman (1972) & 0.95 & 0.050 & & - & - \\
Panofsky et al. (1977) & - & - & & 1.30 & 3.00 \\
De Bruin et al. (1993)* & 0.95 & 0.035 & & - \\
Kustas et al. (1994) & 1.1 & 0.085 & & - \\
Kaimal and Finnigan (1994)* & 1.05 & 0.040 & & 1.25 & 3.00 \\
Toda and Sugita (2003) & 0.99 & 0.060 & & 1.25 & 3.00 \\
Choi et al. (2004)* & 1.14 & 0.030 & & 1.12 & 2.80 \\
\hline
\end{tabular}

*constants obtained from $\sigma_{T} / T_{*}=C_{1}\left(1-C_{2}\left[\left(z-z_{d}\right) / L\right]\right)^{-\frac{1}{3}}$ the total sum of weights and $P_{3 D}$ is the aerodynamic porosity of vegetation. The weighted frontal area of buildings and vegetation is determined separately $\left(W_{f, b}\right.$ and $\left.W_{f, v}\right)$, treating vegetation as non-porous.

Including vegetation, the $\mathrm{Mac}$ method becomes (Kent et al. 2017a):

$\operatorname{Mac}_{z d}=\left[1+\alpha^{-\lambda_{p}}\left(\lambda_{p}-1\right)\right] H_{a v}$

$M a c_{z 0}=\left(\left(1-\frac{z_{d}}{H_{a v}}\right) \exp \left[-\left(0.5 \beta \frac{C_{D b}}{k^{2}}\left(1-\frac{z_{d}}{H_{a v}}\right) \frac{\left\{W_{f, b}+W_{f, v}\left(P_{v}\right)\right\}}{W_{A T}}\right)^{-0.5}\right]\right) H_{a v}$

where $C_{D b}=1.2$ is the drag coefficient for buildings and $\alpha=4.43$ and $\beta=1.0$ are empirical constants for staggered arrays fit to the wind tunnel data of Hall et al. (1996). $P_{v}$ is the ratio between the drag coefficient for vegetation with varying $P_{3 D}$ and buildings (Kent et al. 2017a):

$P_{v}=\frac{-1.251 P_{3 D}^{2}+0.489 P_{3 D}+0.803}{C_{D b}}$

derived from experiments with $0 \leq P_{3 D} \leq 0.85$ (Guan et al. 2000). The Kan method is a development of the Mac method, incorporating roughness-element height variability (Kanda et al. 2013):

$\operatorname{Kan}_{z_{d}}=\left[C_{0} X^{2}+\left(a_{0} \lambda_{p}^{b_{0}}-C_{0}\right) X\right] H_{\max }$,

$X=\frac{\sigma_{H}+H_{a v}}{H_{\max }}$

and

$\operatorname{Kan}_{z_{0}=}\left(b_{1} Y^{2}+c_{1} Y+a_{1}\right) M a c_{z_{0}}$,

$Y=\frac{\lambda_{p} \sigma_{H}}{H_{a v}}$

where $0 \leq X \leq 1,0 \leq Y$ and $a_{0}, b_{0}, c_{0}, a_{1}, b_{1}$ and $c_{1}$, are regressed constants of $1.29,0.36,-0.17,0.71,20.21$ and -0.77 .

The methods are applicable to any combination of buildings and vegetation, with vegetation phenology and associated drag characteristics being optimisable (through $P_{3 D}$ ). With this information being scarce, and the predominance of deciduous vegetation at both sites it is assumed that all vegetation has a leaf-on porosity of $20 \%$ and leaf-off porosity of $60 \%$ (i.e. $P_{3 D}=0.2$ and $P_{3 D}=0.6$, respectively, Heisler 1984; Heisler and DeWalle 1988, Grimmond and Oke 1999). During leaf-on and leaf-off transition an intermediate porosity may be used 

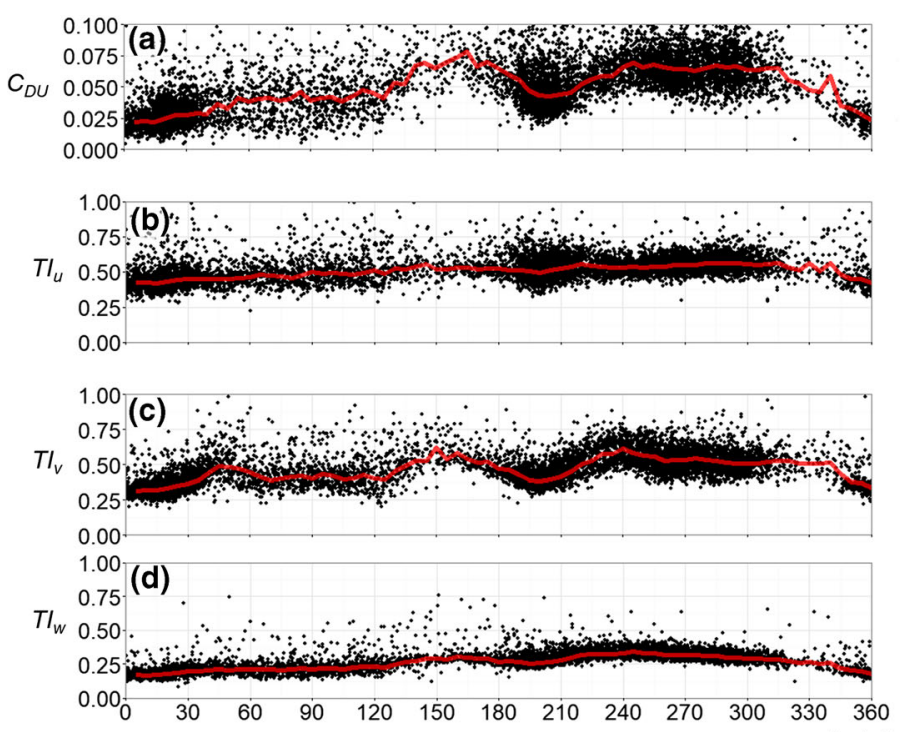

wind direction $\left(^{\circ}\right)$
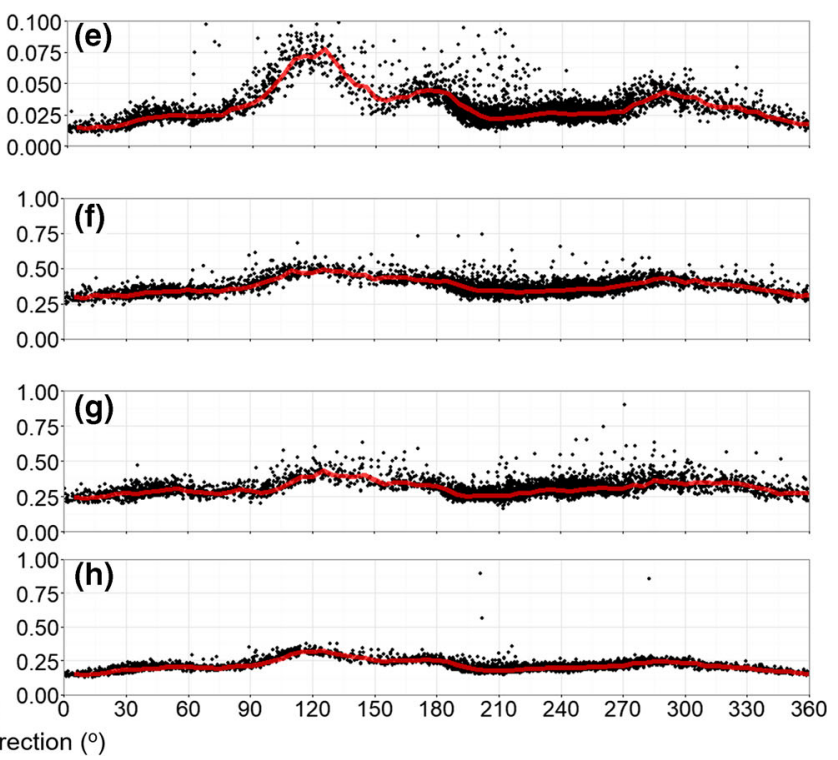

Fig. 3 All 30-min observations during neutral conditions (black dots) at the (a-d) Seoul Forest Park (SFP) and (e-h) Swindon (SWD) sites: (a, e) Aerodynamic drag coefficient $\left(C_{D U}=\left(u_{*} / \bar{U}_{z}\right)^{2}\right)$ and turbulence intensities in the (b, f) longitudinal $\left(T I_{u}=\sigma_{u} / \bar{U}_{z}\right)$, (c, g) transverse $\left(T I_{v}=\sigma_{v} \bar{U}_{z}\right)$ and $(\mathbf{d}, \mathbf{h})$ vertical $\left(T I_{w}=\sigma_{w} \bar{U}_{z}\right)$ wind directions. Neutral conditions are $\left|\left(z_{m}-z_{d}\right) / L\right| \leq 0.05$ ( $L$ is Obukhov length,

(e.g. $\left.P_{3 D}=0.4\right)$. However, the rapid transition at both sites $(<$ 30 days) means there is insufficient data to investigate the transition periods here.

Determination of source-area weighted aerodynamic parameters using the morphometric methods (including vegetation) are implemented into the Urban Multi-scale Environmental Predictor (UMEP, http://www.urban-climate. net/umep/UMEP) climate service plugin for the open source software QGIS (Lindberg et al. 2018).

\section{Results}

\section{Impact of roughness elements on observational data}

To assess the disturbance to measurements from nearby roughness elements the turbulence data are inspected (Fig. 3). At the SFP site, the data are more variable due to the proximity to roughness elements (measurements are at $1.6 H_{a v}$ of all roughness elements in the $300-\mathrm{m}$ radius) (Fig. 3a-d). In some directions $z_{m}$ is similar to $H_{a v}(\mathrm{~N}, \mathrm{SW}, \mathrm{W}, \mathrm{NW}$, Table $4 \mathrm{~b}$ ), and $H_{\max }$ is always larger than $z_{m}$. Therefore, the measurements are probably within the roughness sublayer (RSL) and $z_{d}$ is often larger than $z_{m}$. A peak in the aerodynamic drag coefficient and transverse turbulence intensity between $130^{\circ}-180^{\circ}$ is likely caused by the rear sides of the sensor (Fig. 3a, c). In addition, there is a larger proportion of drag between $210^{\circ}-330^{\circ}$ where taller roughness elements are located (Fig. 3a). $z_{m}=12.2 \mathrm{~m}$ at SFP and $12.5 \mathrm{~m}$ at SWD, $z_{d}$ is assumed as $H_{a v}=8 \mathrm{~m}$ at SFP and $4.5 \mathrm{~m}$ at SWD). Red line is the median for each $5^{\circ}$ wind direction. $\bar{U}_{z}$ is the average wind speed, $u_{*}$ is the friction velocity and $\sigma_{u}, \sigma_{v}$ $\sigma_{w}$ are the standard deviations of the longitudinal, transverse and vertical velocity components of the wind

Although the TVM and WVM methods have been demonstrated to be appropriate in the RSL, the calculation of source areas is more uncertain (e.g. Baldocchi 1997, Rannik et al. 2000, Sogachev and Lloyd 2004, Vesala et al. 2008, Leclerc and Foken 2014). However, Fig. 3a-d demonstrates there is still some homogeneity to the flow and to characterise the local roughness, the Kormann and Meixner (2001) footprint model is applied at a height likely greater than the RSL $\left(2.5 H_{a v}=20 \mathrm{~m}\right)$.

At the SWD site, the measurement height is approximately $2.8 H_{a v}$ based on the measurement source area. Combined with a lack of disturbance to turbulence data for most directions (Fig. 3e-h), this indicates measurements are taken within the inertial sublayer (ISL), where it is most appropriate to apply the anemometric methods and source area calculations. Peaks in turbulence data between $100^{\circ}$ and $140^{\circ}$ and at approximately $180^{\circ}$ and $280^{\circ}$ (Fig. 3e-h) are likely caused by houses with maximum heights of up to $8 \mathrm{~m}-10 \mathrm{~m}$ in these directions (within $25 \mathrm{~m}$ of the sensor).

\section{Land cover and geometry surrounding the sites}

Source areas indicate the likely surface influencing turbulent fluxes measured at a point (Schmid and Oke 1990, Schmid 1997, Leclerc and Foken 2014) and can therefore be used to characterise site surroundings, with varying certainty (Heidbach et al. 2017). Source area characterisation is performed for the SWD site. However, at the SFP site, the 
Table 4 Characteristics within a 300-m radius of the Seoul Forest Park site by direction ( $45^{\circ}$ sectors, $\pm 22.5^{\circ}$ of the stated direction): (a) Land cover and (b) Geometry of roughness elements $>2 \mathrm{~m}$. 'Other' land cover is predominantly comprised of a water works (with few roughness elements $>2 \mathrm{~m}$ ), which cannot be classified from aerial imagery

\begin{tabular}{|c|c|c|c|c|c|c|c|c|}
\hline Direction & Building & $\begin{array}{l}\text { Impervious } \\
\text { (road) }\end{array}$ & $\begin{array}{c}\text { Impervious } \\
\text { (non-road) }\end{array}$ & Water & Vegetation & Grass & Other & Bare-soil \\
\hline $\mathrm{N}$ & 12 & 7 & 0 & 7 & 40 & 0 & 0 & 34 \\
\hline $\mathrm{NE}$ & 18 & 4 & 5 & 3 & 49 & 8 & 0 & 13 \\
\hline $\mathrm{E}$ & 1 & 0 & 0 & 4 & 54 & 33 & 0 & 8 \\
\hline SE & 8 & 1 & 3 & 4 & 68 & 0 & 2 & 14 \\
\hline $\mathrm{S}$ & 5 & 6 & 0 & 0 & 48 & 0 & 39 & 2 \\
\hline SW & 2 & 25 & 1 & 0 & 54 & 0 & 8 & 10 \\
\hline W & 16 & 29 & 20 & 0 & 33 & 0 & 0 & 2 \\
\hline NW & 16 & 33 & 15 & 0 & 30 & 2 & 0 & 4 \\
\hline
\end{tabular}

(b) Geometry

Direction

Buildings

$\sigma_{H}$

8.43

$\mathrm{N}$

$\mathrm{NE}$

12.65

$H_{\max }$

33.4

E

SE

$S$

SW

W

NW
16.53

7.38

11.57

12.83

6.68

8.82

16.93

27.67

26.45

\subsection{3}

2.80

1.92

1.06

4.75

6.93

5.32

\begin{tabular}{lccll}
\multicolumn{5}{c}{ Vegetation } \\
$H_{a v}$ & $H_{\max }$ & $\sigma_{H}$ & $\lambda_{p}$ & $\lambda_{f}$ \\
7.5 & 28.06 & 3.7 & 0.33 & 0.38 \\
7.63 & 22.16 & 2.81 & 0.44 & 0.29 \\
7.56 & 21.91 & 2.57 & 0.43 & 0.34 \\
6.98 & 19.43 & 2.73 & 0.47 & 0.34 \\
5.76 & 17.51 & 3.17 & 0.41 & 0.31 \\
7.64 & 22.86 & 3.39 & 0.40 & 0.25 \\
8.14 & 18.84 & 3.37 & 0.25 & 0.24 \\
9.47 & 20.74 & 3.62 & 0.20 & 0.20 \\
\hline
\end{tabular}

$$
0.11
$$

0.13

0.00

0.05

0.05

0.02

0.15

0.08

$\lambda_{f}$
0.07
0.02
0.00
0.03
0.01
0.01
0.12
0.09

Geometry abbreviations: $H_{a v}$ - average height, $H_{\max }-$ maximum height, $\sigma_{H}-$ standard deviation of heights, $\lambda_{p}-$ plan area index, $\lambda_{f}-$ frontal area index

uncertainty in the calculated source areas and the large $z_{d}$ compared to $z_{m}$ means $45^{\circ}$ direction sectors are used.

Aerodynamic characteristics are expected to be dominated by the tall and abundant vegetation at the SFP site, rather than by the sparse buildings. The average vegetation height $\left(H_{a v, v}\right)$ ranges between 5 and $10 \mathrm{~m}$ and with a maximum $\left(H_{\max , v}\right)$ of $\geq$ $17.5 \mathrm{~m}$ in all directions it is over double $H_{a v}$. The plan and frontal area indexes of vegetated roughness elements $\left(\lambda_{p, v}\right.$ and $\lambda_{f, v}$, respectively) are consistently $>0.3$, whereas buildings have plan and frontal area indexes $\left(\lambda_{p, b}\right.$ and $\left.\lambda_{f, b}\right)$ consistently

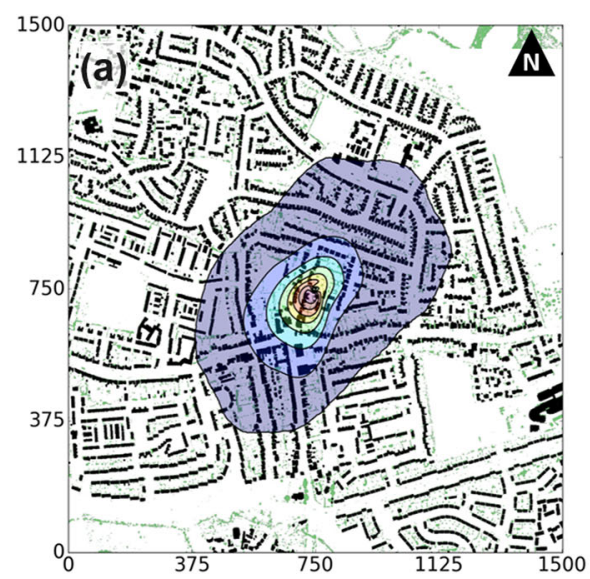

$\mathrm{m}$

Fig. 4 Source area climatology of the Swindon site (SWD) modelled using the Kormann and Meixner (2001) source area model for the months of June, July and August (Leaf-on) in 2011 and 2012. Source areas are modelled using aerodynamic parameters from the (a) Kanda et al. (2013)

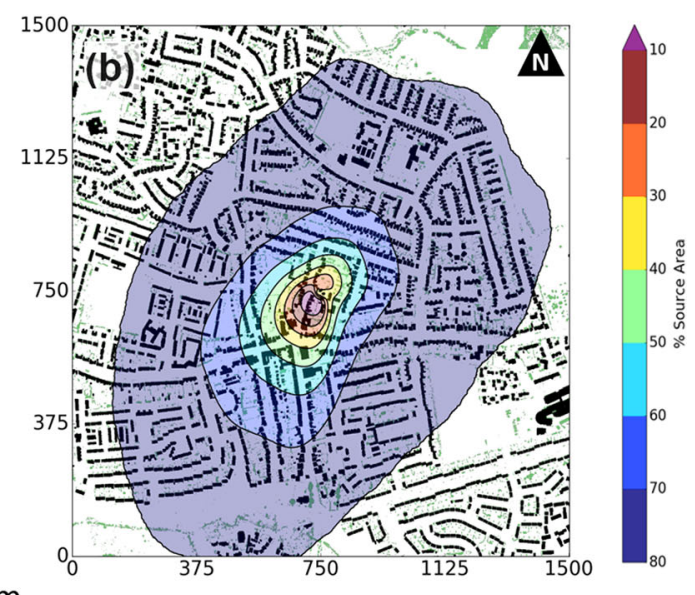

and (b) Macdonald et al. (1998) morphometric methods. The $80 \%$ cumulative source area weights for each 30-min average of observations are integrated and normalised by the sum of all weightings $(n=8787)$. Source areas overlain upon buildings (black) and vegetation (green) $>2 \mathrm{~m}$ 
Table 5 Roughness-element characteristics in the source areas modelled during leaf-on conditions at SWD using the (a) Kanda et al. (2013, Kan) and (b) Macdonald et al. (1998, Mac) morphometric methods (Fig. 4) for all observations $(n=8787)$ and in the specified north-easterly (NE) $(n=911)$ and south-westerly (SW) $(n=2045)$ directions

\begin{tabular}{|c|c|c|c|c|c|c|c|c|c|c|c|c|}
\hline \multirow[t]{2}{*}{ Direction } & \multicolumn{6}{|c|}{ Buildings } & \multicolumn{6}{|c|}{ Vegetation } \\
\hline & $H_{a v}$ & $H_{\max }$ & $\sigma_{H}$ & $\lambda_{p}$ & $\lambda_{f}$ & Cover $(\%)$ & $H_{a v}$ & $H_{\max }$ & $\sigma_{H}$ & $\lambda_{p}$ & $\lambda_{f}$ & Cover (\%) \\
\hline \multicolumn{13}{|l|}{ (a) Kan } \\
\hline All & 4.74 & 10.05 & 1.59 & 0.24 & 0.13 & 11 & 3.49 & 12.08 & 1.58 & 0.05 & 0.11 & 2 \\
\hline $\mathrm{NE}\left(030^{\circ}-090^{\circ}\right)$ & 3.92 & 9.80 & 1.31 & 0.15 & 0.06 & 6 & 3.88 & 13.03 & 1.70 & 0.07 & 0.14 & 4 \\
\hline $\mathrm{SW}\left(210^{\circ}-240^{\circ}\right)$ & 4.52 & 10.40 & 1.66 & 0.30 & 0.15 & 14 & 3.35 & 12.33 & 1.59 & 0.04 & 0.10 & 2 \\
\hline \multicolumn{13}{|l|}{ (b) Mac } \\
\hline All & 4.67 & 11.96 & 1.65 & 0.24 & 0.12 & 11 & 3.51 & 14.46 & 1.76 & 0.05 & 0.10 & 2 \\
\hline $\mathrm{NE}\left(030^{\circ}-090^{\circ}\right)$ & 3.95 & 12.03 & 1.41 & 0.17 & 0.07 & 7 & 3.82 & 14.79 & 1.73 & 0.07 & 0.13 & 3 \\
\hline $\mathrm{SW}\left(210^{\circ}-240^{\circ}\right)$ & 4.62 & 12.01 & 1.73 & 0.30 & 0.14 & 13 & 3.39 & 13.76 & 1.61 & 0.04 & 0.09 & 2 \\
\hline
\end{tabular}

Geometry abbreviations: $H_{a v}$ average height, $H_{\max }$ maximum height, $\sigma_{H}$ standard deviation of heights, $\lambda_{p}$ plan area index, $\lambda_{f}$ frontal area index. Cover is the weighted percentage of pixels in the source area which are in the BSM for buildings and CDSM for vegetation

$<0.1$ (Table $4 \mathrm{~b}$ ). An exception is to the north and west where the built fraction increases to close to $20 \%$ due to the RMC factory (Fig. 2a).

Source area size varies with the model and parameters used (e.g. Leclerc and Foken 2014, Heidbach et al. 2017), as demonstrated with aerodynamic parameters $\left(z_{d}\right.$ and $\left.z_{0}\right)$ from the Kan and Mac morphometric methods (Fig. 4). Independent of morphometric method, the SWD site source areas include residential housing, back gardens and impervious driveways. The source area climatology is biased towards the predominant south-westerly wind direction, where it also extends further upwind because of the greater wind speeds in this direction.

The Mac method source areas are larger than the Kan method (average upwind extents of $700 \mathrm{~m}$ and $400 \mathrm{~m}$, respectively) due to the difference in aerodynamic parameters determined with each method. The peak flux footprint is $50 \mathrm{~m}$ upwind for the Mac method and $25 \mathrm{~m}$ upwind for Kan (Fig. 4). Although these differences impact the surface geometry and land cover determined within the source area, the consistent fetch at the SWD site means the parameters determined by the Mac and Kan source areas are remarkably similar (Table 5). The source area has $11 \%$ built and $2 \%$ vegetated roughness elements, with low-level vegetation (i.e. small shrubs), grass, impervious materials (e.g. roads or driveways) and soil forming the remainder. The latter have a comparatively small impact on the aerodynamic roughness parameters at the neighbourhood scale. The average height of vegetation is smaller than buildings $(\sim 3.5 \mathrm{~m}$ and $4.7 \mathrm{~m}$, respectively), but the maximum tree height (up to $15 \mathrm{~m}$ ) is slightly larger than buildings (up to $12 \mathrm{~m}$ ). To the north-east $\left(030^{\circ}-090^{\circ}\right)$, trees are tallest and most abundant, whilst vegetation is least to the south-west (Fig. 2f, $210-$ $\left.240^{\circ}\right)$.

\section{Aerodynamic parameters}

\section{Seoul Forest Park (SFP)}

At the SFP site, the anemometrically determined $z_{d}$ is relatively insensitive to both the 'universal' constants (Table 3) and initial $z_{d}$ used to define stability. Both consistently cause a maximum variability of $<1 \mathrm{~m}$ for any $10^{\circ}$ wind sector (Fig. 5a and b, shading around grey and brown lines) which corresponds to $<10 \%$ of the median $z_{d}$. Despite the proximity of measurements to roughness elements, the maximum RMSE between $\phi_{e s t}$ and $\phi_{o b s}$ for the wind variance method is 0.4 , which is similar to observations which are higher above roughness elements in other urban areas (Kent et al. 2017a) and provides greater confidence when using the WVM. In contrast, the RMSE for the TVM is much larger (2.0), because of the proximity to roughness elements, the thermal inhomogeneity of the area (i.e., water, grasses, trees, bare-soil, and impervious surfaces, Table 4) and the dissimilarity of roughness length between momentum and heat (e.g. Owen and Thomson 1963, Zilitinkevich 1995, Voogt and Grimmond 2000, Hong et al. 2012).

Both the TVM and WVM indicate $z_{d}$ may be larger than $z_{m}(12.2 \mathrm{~m})$ for all wind directions (Fig. 5a, b). Both methods have a larger $z_{d}$ during leaf-on (Fig. 5a) than leaf-off (Fig. 5b), which is approximately $1 \mathrm{~m}$ larger for the TVM and 2-4 m larger for the WVM. A seasonal increase in $z_{d}$ is also observed by Giometto et al. (2017) for a suburban neighbourhood with the larger amount of leaf-on foliage exerting greater drag upon the flow, acting to raise the centroid of the drag profile (analogous to $z_{d}$, Jackson 1981).

The anemometric $z_{d}$ is more variable with wind direction during leaf-on, which can be directly related to trees (and 

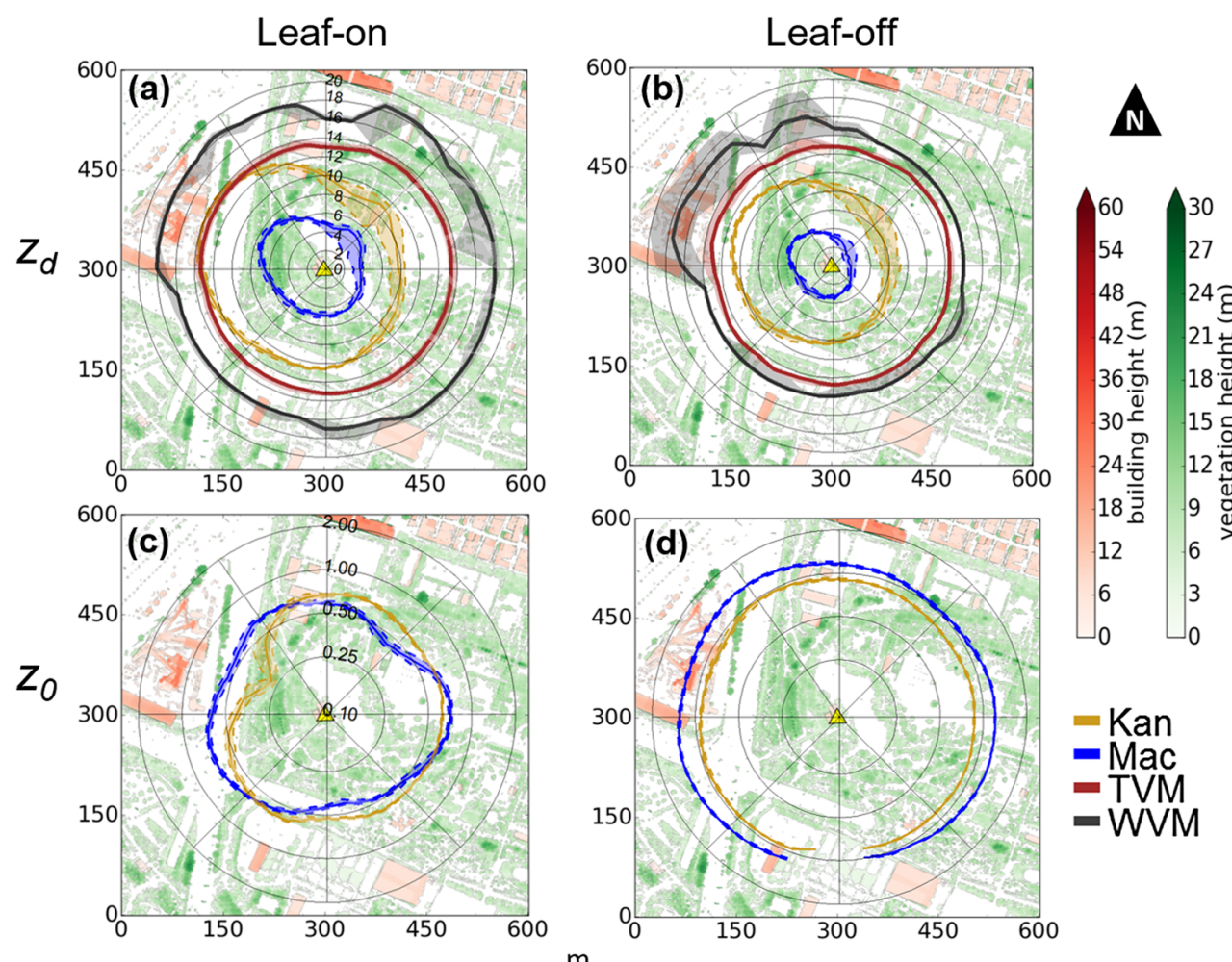

Fig. 5 Median aerodynamic parameters determined for $10^{\circ}$ wind sectors surrounding Seoul Forest Park site (SFP). Seasons (columns) are: leaf-on (June, July, August) and leaf-off (December, January, February). Anemometric methods: TVM (temperature variance, Rotach 1994); WVM (wind variance, Toda and Sugita 2003), with the range of solutions (shading) provided from varying constants used during application of the methods and initial $z_{d}$ used to define stability. Morphometric methods: Kan (Kanda et al. 2013); Mac (Macdonald et al. 1998) applied using the

Kormann and Meixner (2001) footprint model for all 30-min observations, with 10 th $/ 90$ th percentile for each $10^{\circ}$ sector shaded. $z_{d}$ is for unstable conditions $\left(6.2 \leq z^{\prime} / L \leq 0.05\right.$, with $z^{\prime}=z_{m}-z_{d}$ and $L$ the Obukhov length) and $z_{0}$ is for neutral conditions $\left(\left|z^{\prime} / L\right| \leq 0.05\right)$. For morphometric method stability definition, $z_{d}$ in $z^{\prime} / L$ is determined by the respective morphometric method. Insufficient neutral conditions for southerly winds during leaf-off vegetation state means no morphometric $z_{0}$ is reported here

implications for $z_{d}$ ). For example, $z_{d}$ is largest between $080^{\circ}-$ $150^{\circ}$, where there is maximum vegetation cover $(>50 \%$ land cover, Table $4 \mathrm{a}$ ), and between $270^{\circ}-010^{\circ}$ where $H_{a v, v}$ is largest (Table $4 \mathrm{~b}$ ). The $6-\mathrm{m}$ variation in $z_{d}$ between $270^{\circ}-$ $360^{\circ}$ during leaf-off (Fig. 5b), is attributed to the disturbance to airflow from the RMC factory approximately $250 \mathrm{~m}$ upwind (Fig. 2a), and a row of trees ( $>20 \mathrm{~m}$ ) just $60 \mathrm{~m}$ upwind. During leaf-on, this variability is not observed because the foliage on the trees dominates airflow disturbance, causing an obvious increase in $z_{d}$ (Fig. 5a).

Similar to the anemometric methods, both morphometric methods indicate leaf-on $z_{d}$ is larger than leaf-off $z_{d}$, (Fig. 5a, b). The effect is least obvious between $000^{\circ}$ and $120^{\circ}$ due to the lake and open grassed area. However, between $120^{\circ}$ to $280^{\circ}$ the increasing height and proportion of vegetation increases both $M a c_{z_{d}}$ and $\mathrm{Kan}_{z_{d}}$, with leaf-on $z_{d} 1-3 \mathrm{~m}$ larger than leaf-off (Table 4b, Fig. 5). Both morphometric methods indicate maximum $z_{d}$ and seasonal signal between $270^{\circ}$ and $330^{\circ}$, a similar direction to the anemometric methods. Here, $M a c_{z_{d}}$ becomes as large as $7.5 \mathrm{~m}$ and $\mathrm{Kan}_{z_{d}}$, with a more

pronounced peak, reaches $14 \mathrm{~m}$. The latter is associated with the increased vegetation plan area, $H_{a v}, H_{\max }$ and $\sigma_{H}$ (Table $4 \mathrm{~b}$ ). As the source area rarely extends to the RMC factory (Fig. 2a), the morphometric $z_{d}$ is primarily a function of vegetation in these directions.

Leaf-off $z_{0}$ is typically $>0.5 \mathrm{~m}$ larger than leaf-on $z_{0}$ for both morphometric methods (Fig. $5 \mathrm{c}, \mathrm{d}$ ), as $z_{0}$ varies with roughness-element density. In canopies with both vegetated (Shaw and Pereira 1982, Wolfe and Nickling 1993, Raupach 1992, 1994, Nakai et al. 2008) and built (Macdonald et al. 1998, Cheng and Castro 2002, Jiang et al. 2008) roughness elements, $z_{0}$ has been demonstrated to increase with density until a peak $\lambda_{f}$ (or leaf area index), beyond which $z_{0}$ decreases again. Therefore, the seasonal change of $z_{0}$ is expected to be canopy dependent: $z_{0}$ will increase with density for sparsely packed canopies, but will decrease with density in dense canopies. The SFP site is an example of the latter, where an already densely packed canopy during leaf-off conditions becomes denser during leaf-on. This effectively closes the canopy creating a smoother surface with a flow more 
characteristic of a skimming regime and reduction in $z_{0}$. The comparatively sparsely packed neighbourhood site analysed by Giometto et al. (2017) is an example of the former, whereby leaf-on transition creates an effectively rougher surface with a flow more characteristic of a wake interference regime and resultant increase in $z_{0}$.

At the SFP site, the seasonal change in $M a c_{z_{0}}$ is more obvious than $\mathrm{Kan}_{z_{0}}$, as the former is more sensitive to $\lambda_{f}$ (e.g. Kent et al. 2017b, their Fig. 1) and $\mathrm{Kan}_{z_{0}}$ considers geometric parameters other than $\lambda_{f}\left(H_{\max }, \sigma_{H}\right.$ and $\left.\lambda_{p}\right) . K_{a n_{z_{0}}}$ is on average $0.2 \mathrm{~m}$ less than $M a c_{z_{0}}$ because the larger $z_{d}$ determined using the Kan method means physically less frontal area of roughness elements exert drag upon the mean wind flow. For both morphometric methods, leaf-off $z_{0}$ is consistent with direction due to the relative lack of foliage (Fig. 5d). However, leaf-on $z_{0}$ is much more directionally variable and similarly to $z_{d}$ can be directly related to vegetation geometry and cover. $M a c_{z_{0}}$ has greater directional variability because of the aforementioned sensitivity to $\lambda_{f}$.

The morphometric methods were applied treating vegetation as buildings (i.e. $P_{3 D}=0$ ) and ignoring it (i.e. $P_{3 D}=1$ ), however, the dominance of vegetation in the area meant the former produced $z_{0}<0.25 \mathrm{~m}$ and the latter $z_{d}<5 \mathrm{~m}$. Furthermore, applying the methods without the vegetation parameterisation does not produce the seasonal change demonstrated by the observations.

\section{Swindon (SWD)}

During leaf-on, median solutions to both the temperature and wind variance methods indicate $z_{d}$ varies between 4 and $10 \mathrm{~m}$ surrounding the SWD site (Fig. 6a). However, the range of $z_{d}$ for any $10^{\circ}$ sector is up to $5 \mathrm{~m}$ for the temperature variance method and up to $2.5 \mathrm{~m}$ for the wind variance method, corresponding to as much as $50 \%$ of median $z_{d}$. This range is larger than previous applications of the methods (e.g. Kent et al. $2017 \mathrm{~b}$ ) and at the SFP site. The $z_{d}$ from the temperature variance method cannot be related to surface characteristics, providing a $z_{d}$ which is consistently close to $z_{m}$ and up to $5 \mathrm{~m}$ larger than the wind variance method. The predominantly large $z_{d}$ solutions are likely because of the thermal inhomogeneity of the area, which includes buildings, vegetated, and paved land cover. Therefore, similar to the SFP site, there is considerable variability between $\phi_{\text {est }}$ and $\phi_{o b s}$ for the temperature variance method (RMSE > 0.6) and less confidence in its use.

The wind variance method indicates $z_{d}$ is consistently between 4 and $5 \mathrm{~m}$ (i.e. similar to $H_{a v}$ ) (Fig. 6a). The directional variability of these results can be directly related to surface
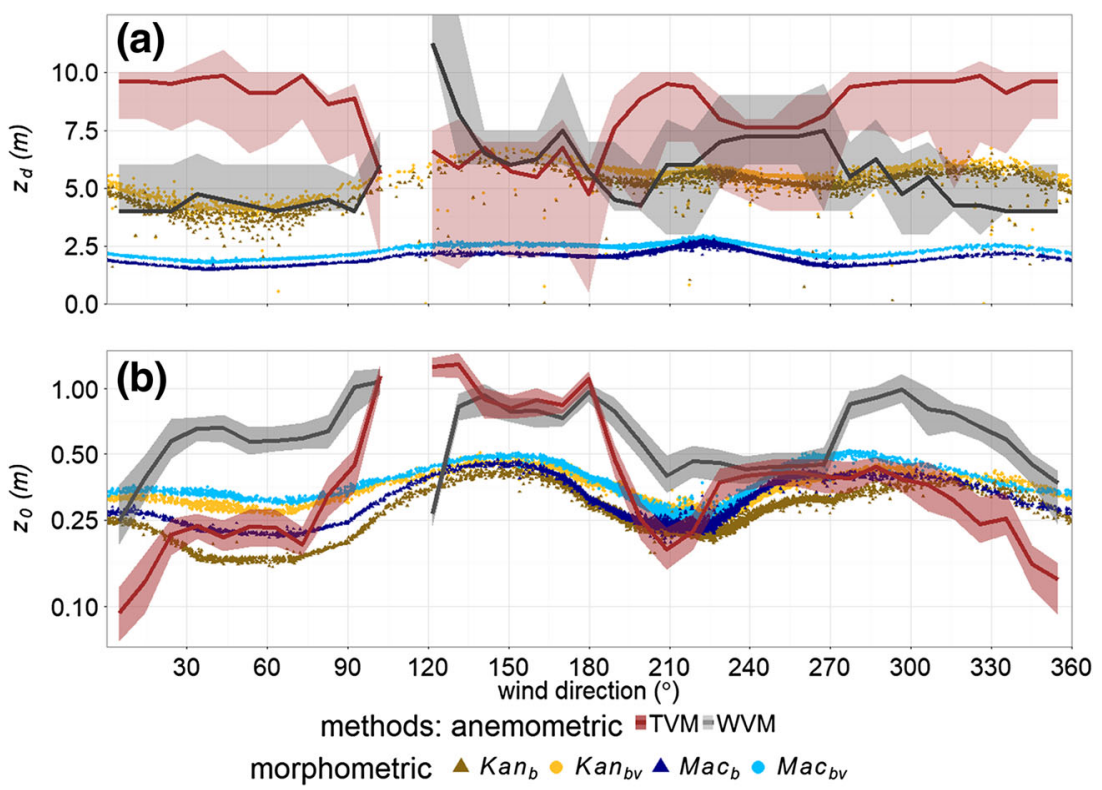

Fig. 6 Comparison of anemometric (lines and shading) and morphometric (points) methods to determine the (a) zero-plane displacement $\left(z_{d}\right)$ and (b) aerodynamic roughness length $\left(z_{0}\right)$ (note log y axis) surrounding the Swindon site (Fig. 2f). For anemometric methods, $z_{d}$ is the median solution of the temperature variance (TVM) and wind variance (WVM) methods, applied to 30-min observations during unstable conditions $\left(6.2 \leq z^{\prime} / L \leq 0.05\right.$, with $z^{\prime}=z_{m}-z_{d}$ and $L$ the Obukhov length) for $10^{\circ}$ sectors. The range (shading) represents all possible solutions by varying $z_{d}$ used for stability definition and varying constants used in the methods. $z_{0}$ is the median (lines) and upper and lower quartile (shaded) of the eddy-covariance method, during neutral conditions $\left(\left|z^{\prime} / L\right| \leq 0.05\right)$ for each $10^{\circ}$ sector, using $z_{d}$ from the TVM and WVM, respectively. Less than 10 observations in the $110^{\circ}$ sector means no values are reported here. The morphometric methods: Kan (Kanda et al. 2013); Mac (Macdonald et al. 1998) are for each source area during the same conditions as the anemometric methods, applied considering vegetation (subscript $b v$ ) and for buildings only (subscript $b$ ). For the morphometric method stability definition, $z_{d}$ in $z^{\prime} / L$ is determined by the respective morphometric method 
characteristics. Combined with the lower RMSE between $\phi_{\text {est }}$ and $\phi_{o b s}(\mathrm{RMSE}<0.2)$, there is greater confidence in the wind variance than the temperature variance method results. Increases of $z_{d}$ and $z_{0}$ of up to $7.5 \mathrm{~m}$ and $1 \mathrm{~m}$, respectively between $130^{\circ}-$ $180^{\circ}$ and $240^{\circ}-280^{\circ}$ are associated with houses within $25 \mathrm{~m}$ of the sensor in these directions. Elsewhere, the larger $z_{d}$ from the temperature variance method means that its associated $z_{0}$ is consistently $0.25 \mathrm{~m}-0.5 \mathrm{~m}$ less than the wind variance method (Fig. $6 b)$.

Relative minima of both $z_{d}$ and $z_{0}$ occur when wind flow is aligned with the smoother road surface to the west of sites between $200^{\circ}-210^{\circ}$ and $330^{\circ}-360^{\circ}$ (Fig. 6a). A relative increase in $z_{0}$ for both methods (to approximately $0.25 \mathrm{~m}$ and $0.75 \mathrm{~m}$ for the temperature and wind variance methods, respectively) in the $045^{\circ}$ direction is likely because of the taller and more abundant vegetation in the same direction. However, there is not a similar increase of $z_{d}$.

For both $z_{d}$ and $z_{0}$ the morphometric methods have less directional variability than the anemometric methods because of the similarity in geometry surrounding the SWD site. When vegetation is considered $\mathrm{Kan}_{z d}$ ranges between $2.5 \mathrm{~m}$ and $7 \mathrm{~m}$ and is therefore approximately $0.5-1.5 H_{a v}$ (Fig. 6a, $\operatorname{Kan}_{b v}$ ). In comparison $\mathrm{Mac}_{z d}$ is consistently half of this, ranging between $0.25-0.75 H_{a v}$ (Fig. 6a, $M a c_{b v}$ ). The $z_{d}$ determined by the morphometric methods is more similar to the wind variance method (than the temperature variance), especially for $\mathrm{Kan}_{z_{d}}$, which has an average difference of $0.2 \mathrm{~m}$. The methods indicate relative minima and maxima of $z_{d}$ in similar directions. A relative reduction between $030^{\circ}-090^{\circ}$ occurs where fewer buildings are located (Table 5), whilst an increase between $130^{\circ}-180^{\circ}$ is associated with the taller buildings close to the sensor and larger $H_{a v}(\sim 5 \mathrm{~m})$.

For aerodynamic roughness length, incorporating vegetation in the morphometric calculations means $z_{0}$ ranges between 0.2 $\mathrm{m}$ and $0.5 \mathrm{~m}$. The similarity of $z_{0}$ between the methods is because the frontal area index ranges between 0.15 and 0.2 , a region that the methods indicate similar $z_{0}$ (Kent et al. 2017b their Fig. 1). However, in directions where the roughness-element frontal area is reduced, $\mathrm{Kan}_{z_{0}}$ can be up to $0.1 \mathrm{~m}$ less than $M a c_{z 0}$. Maxima between $120^{\circ}-190^{\circ}$ and $270^{\circ}-280^{\circ}$ are because of the taller houses. When wind flow is aligned with the smoother surface of the road to the west $\left(210^{\circ}-250^{\circ}\right)$ values are lower. Morphometrically determined $z_{0}$ are within the anemometric range, except when increased friction velocity from nearby roughness elements creates an anemometric $z_{0}$ that is double the morphometric results (Fig. $6 \mathrm{~b}, 120^{\circ}-180^{\circ}$ ).

When the morphometric methods are applied without considering vegetation, the average reduction of $z_{d}$ is $0.3 \mathrm{~m}$ and $z_{0}$ is $0.1 \mathrm{~m}$ (Fig. $7 \mathrm{~b}, \mathrm{Kan}_{b}$ and $M a c_{b}$ ). However, these values are directionally dependent. For example, not considering the taller and more abundant vegetation between $030^{\circ}-090^{\circ}$ means $z_{d}$ and $z_{0}$ are reduced with an average of up to $20 \%$ and $40 \%$, respectively, for both morphometric methods. Giometto et al. (2017) also demonstrate overlooking vegetation leads to a reduction of up to $50 \%$ in both $z_{d}$ and $z_{0}$ for a neighbourhood site with a larger plan area of vegetation and taller trees than the SWD site. Both results highlight the importance of considering vegetation during aerodynamic parameter determination.

\section{Similarities in aerodynamic parameter analysis between the sites}

The variability in the anemometric methods and the interdependence of $z_{d}$ and $z_{0}$ (i.e. the former is used when determining the latter, Eq. 3) means it is difficult to use the anemometric methods as a basis for the most appropriate magnitude of $z_{d}$ and $z_{0}$. However, there are apparent similarities from the aerodynamic parameter analysis performed at both sites. There is greater uncertainty in the application of the temperature variance method to determine $z_{d}$, than the wind variance method. The RMSE between $\phi_{\text {est }}$ and $\phi_{o b s}$ of the former are consistently twice the latter, which is attributed to the thermal inhomogeneity of both sites and dissimilarity of roughness length between momentum and heat. Greater uncertainty was also found in the temperature variance method in a central urban area (Kent et al. 2017b).

As with previous applications, $z_{d}$ determined using the temperature and wind variance methods at both sites indicates $z_{d}$ is larger than $H_{a v}$ (e.g. Grimmond et al. 1998, 2002, Feigenwinter et al. 1999, Kanda et al. 2002, Tsuang et al. 2003, Christen 2005, Chang and Huynh 2007, Tanaka et al. 2011, Kent et al. 2017b). Additionally, morphometric $z_{d}$ results are consistently smaller than anemometric results. However, the direct incorporation of height variability in $\mathrm{Kan}_{z d}$ means it is more similar to the anemometric methods than $M a c_{z_{d}} . M a c_{z_{d}}$ is less than $H_{a v}$ and may be appropriate for homogeneous groups of roughness elements. However, recent literature demonstrates that the disproportionate amount of drag imposed by taller roughness elements in a heterogeneous mix means $z_{d}$ may indeed become larger than $H_{a v}$ (Jiang et al. 2008, Xie et al. 2008, Hagishima et al. 2009, Zaki et al. 2011; Millward-Hopkins et al. 2011, Tanaka et al. 2011, Kanda et al. 2013). This is particularly evident during leaf-on conditions at the SFP site (Fig. 5a), where $z_{d}$ appraoches $2 H_{a v}$

The contrast in magnitude of aerodynamic parameters determined using the Kan and Mac morphometric methods $\left(\mathrm{Kan}_{z_{d}}\right.$ is typically twice $M a c_{z_{d}}$ ) relates to the Kan method's direct consideration of roughness-element height variability. However, as the Kan method, is developed from Mac, their directional variability is similar. At both sites, the morphometric methods show similar directional variability to the anemometric methods, indicating sound performance of Kent et al.'s (2017a) vegetation parameterisation. 


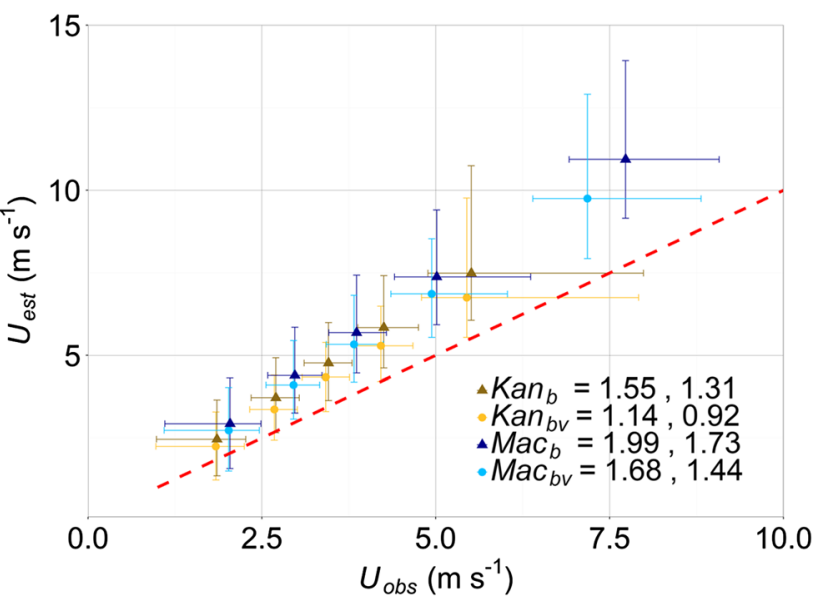

Fig. 7 Observed $\left(U_{\text {obs }}\right)$ and estimated $\left(U_{\text {est }}\right.$, Eq. 10$)$ wind speeds for each 30-min period (at the SWD site) using the Kanda et al. (2013, Kan) and Macdonald et al. (1998, Mac) morphometric methods, considering both buildings and vegetation (subscript $b v$ ) and only buildings (subscript $b$ ). Data are binned from lowest wind speed in groups of 1250 (30-min) data points. Median (points) and 5th and 95th percentiles shown. The rootmean-square error then mean absolute error $\left(\mathrm{m} \mathrm{s}^{-1}\right)$ (between $U_{\text {est }}$ and $\left.U_{o b s}\right)$ are given in the legend

For both morphometric methods, the range of $z_{d}$ and $z_{0}$ for any direction is consistently within $\pm 1 \mathrm{~m}$ and $0.2 \mathrm{~m}$ of the median, respectively (Fig. 5 shading and Fig. 6 range of points for a direction). The range is attributed to the source area variability with meteorological conditions. For example, a wider range between $000^{\circ}-120^{\circ}$ at the SFP site is caused by the proportion of the source area which falls upon the lake, grassed area and surrounding trees (Fig. 5).

\section{Implications for wind-speed estimation}

With pre-determined $z_{d}$ and $z_{0}$, the logarithmic wind law can be used to model the neutral vertical profile of wind speed (Tennekes 1973):
$\bar{U}_{z}=\frac{u *}{\kappa} \ln \left(\frac{z-z_{d}}{z_{0}}\right)$

which theoretically only applies in the inertial sublayer (ISL), where vertical fluxes of momentum can be assumed constant with height (e.g. Tennekes 1973). Closer to a rough surface (i.e. within the RSL) the roughness-element wakes create a highly variable flow which may deviate considerably from Eq. 10 (e.g. Thom et al. 1975, Simpson et al. 1998, KastnerKlein and Rotach 2004, Christen 2005, Harman and Finnigan 2007, Barlow and Coceal 2009, Giometto et al. 2016). With measurements at the SFP site $\left(1.6 H_{a v}\right)$ closer to the roughness elements, there is greater confidence to use Eq. 10 at the SWD site (where $z_{m}=2.8 H_{a v}$ ).

To assess the vegetation parameterisation within the Kan and Mac morphometric methods, the wind speeds measured at the SWD site during neutral conditions $\left(\left|z^{\prime} / L\right|<0.05\right)$ are estimated using Eq. 10 with the observed $u_{*}$ for each 30-min period and roughness parameters determined with, and without vegetation (Fig. 6, subscript $b v$ with and $b$ without vegetation). The estimated wind speed $\left(U_{e s t}\right)$ is regressed against the mean observed wind speed $\left(U_{o b s}\right)$ for the corresponding time period (Fig. 7). As the RMSE has been demonstrated to disproportionately amplify the error associated with outliers when assessing model performance (Willmott and Matsuura 2005), both the RMSE and mean absolute error (MAE) between $U_{\text {est }}$ and $U_{\text {obs }}$ are reported.

Wind speeds are overestimated in over $90 \%$ of cases, which is more apparent at higher $U_{o b s}$ (Fig. 7). Overestimation could be for several reasons, including uncertainty of the use of the logarithmic wind law closer to roughness elements or the appropriateness of $z_{d}$ and $z_{0}$ values obtained from the different methods (e.g. Millward-Hopkins et al. 2012). However, irrespective of the morphometric method $U_{\text {est }}$ most resembles $U_{o b s}$ when aerodynamic parameters determined considering vegetation and buildings are used. For example, wind speeds estimated using $K_{a n}$ and $M a c_{b v}$ have
Fig. 8 As for Fig. 7, but for wind directions between: (a) $210^{\circ}$ $240^{\circ}$ and (b) $030^{\circ}-090^{\circ}$. Each point represents a 30 -min period of observations (data are not binned)
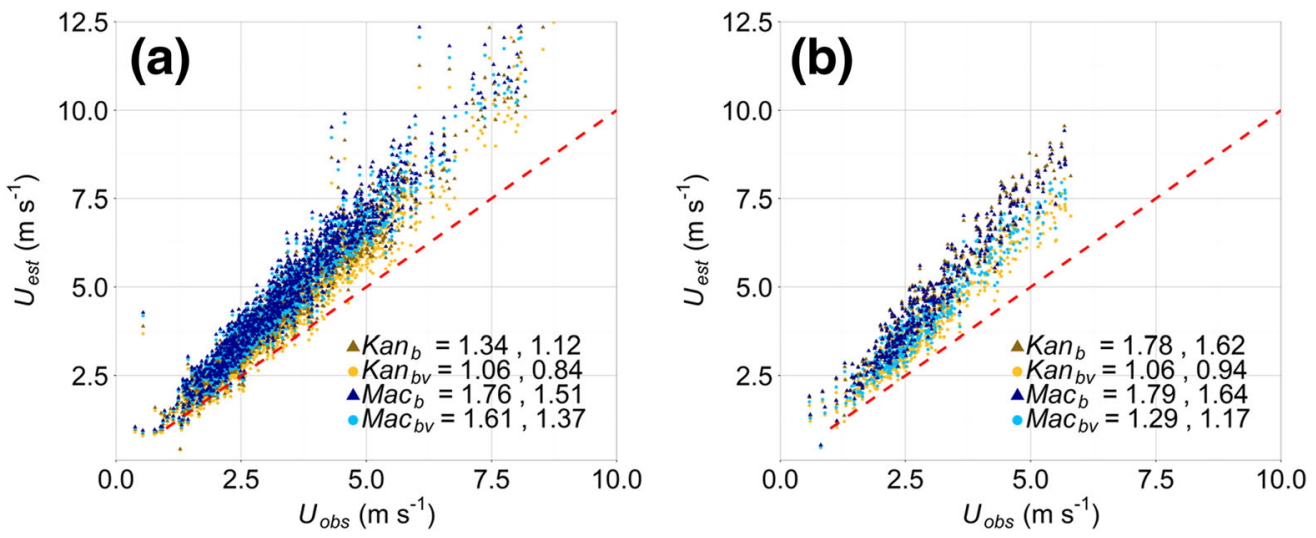
MAE from $U_{o b s}$ of 0.92 and $1.44 \mathrm{~m} \mathrm{~s}^{-1}$, respectively, whereas ignoring vegetation (i.e. $K_{a n}$ and $M a c_{b}$ ) the MAE is $>0.3 \mathrm{~m}$ $\mathrm{s}^{-1}$ larger for both methods $\left(1.31\right.$ and $1.73 \mathrm{~m} \mathrm{~s}^{-1}$, respectively). The lower errors (both RMSE and MAE) associated with the Kan method indicate that regardless of whether vegetation is considered, incorporating height variability improves windspeed estimates.

Similar comparisons between $U_{\text {est }}$ and $U_{\text {obs }}$ are performed for wind directions with the least $\left(210^{\circ}-240^{\circ}\right)$ and greatest $\left(030^{\circ}-090^{\circ}\right)$ vegetated roughness elements (Fig. 8a and b, respectively). As the least vegetated directions have similar aerodynamic parameters (Fig. 6) their associated $U_{\text {est }}$ are similar irrespective of whether vegetation is considered or not. However, despite the small number of trees, accounting for them still reduces the error in wind speed estimation (i.e. the lower errors of $K a n_{b v}$ and $M a c_{b v}$ ) (Fig. 8a). The importance of considering height variability is apparent again, as the Kan method reduces the errors from $U_{o b s}$ by over $0.5 \mathrm{~m} \mathrm{~s}^{-1}$, in comparison to the Mac method.

As expected, in directions with maximum vegetation (tree) cover $\left(030^{\circ}-090^{\circ}\right)$ the impact on estimated wind speeds is greatest. Inclusion of vegetation consistently results in an improvement of wind-speed estimation of over $0.5 \mathrm{~m} \mathrm{~s}^{-1}$ (Fig. 8b). The smallest differences between the errors associated with $K_{a n} n_{b v}$ and $M a c_{b v}$ occur in this direction $\left(0.2 \mathrm{~m} \mathrm{~s}^{-1}\right)$. Combined with the errors for $\mathrm{Kan}_{b}$ being larger than $M a c_{b \mathrm{v}}$, the incorporation of vegetation appears more important for accurately estimating the wind speeds than considering height variability (in this case).

\section{Conclusions}

Two anemometric and two morphometric methods are used to determine the zero-plane displacement $\left(z_{d}\right)$ and aerodynamic roughness length $\left(z_{0}\right)$ for an urban park and a suburban neighbourhood. The anemometric methods use in-situ single-level high frequency observations and therefore inherently include the presence and state of vegetation. The morphometric methods have been developed for bluff bodies only, however a new parameterisation (Kent et al. 2017a) to consider both buildings and vegetation is explored.

At both sites, $z_{d}$ determined using the anemometric methods is larger than the morphometric methods. There is greater uncertainty in an anemometric method based upon scaled temperature variance, as opposed to the vertical wind velocity variance, likely because of the thermal inhomogeneity of the sites. However, the Kanda et al. (2013) morphometric method, which directly considers roughness-element height variability, is consistently most similar to observations, indicating $z_{d}$ is larger than average roughness-element height at the respective sites.

Inter-seasonal analysis is performed at the urban park, which is predominantly vegetation, with few buildings. Both anemometric methods indicate $z_{d}$ during leaf-on vegetation state is up to 1-4 m larger than leaf-off. In addition, leaf-on $z_{d}$ is obviously larger in directions with taller, or a greater proportion of, vegetated roughness elements. The morphometric methods with the vegetation parameterisation have a similar magnitude and directional variability of change, indicating leaf-on $z_{d}$ is $1-3 \mathrm{~m}$ larger than leaf-off, which varies with upwind roughness elements. When the anemometric $z_{d}$ is similar to, or larger than, the measurement height $z_{0}$ cannot be determined from observations. However, the morphometric methods indicate leaf-on $z_{0}$ may be less than half leaf-off $z_{0}$ because the additional tree foliage in an already densely packed area creates an effectively smoother canopy.

The suburban neighbourhood has a larger proportion of buildings than trees. Morphometric analyses are undertaken during leaf-on conditions with and without vegetation. Where there is confidence in the anemometric methods, their $z_{d}$ and $z_{0}$ can be directly related to surface characteristics surrounding the site. The morphometric methods have similar directional change to the anemometric methods, but with less variability as the geometry of the site surroundings are similar. If vegetation is ignored in the morphometric calculations, $z_{d}$ and $z_{0}$ decrease by to $20 \%$ and $40 \%$, respectively.

Wind speeds estimated at the suburban site using the logarithmic wind law and aerodynamic parameters from the morphometric methods are compared to observed wind speed at approximately three times the average roughness-element height. Wind-speed estimations most resemble observations when vegetation (in addition to buildings), as well as the height variability of roughness elements are considered. The consideration of vegetation is more important than the roughness-element height variability in directions where vegetation cover is maximal.

Kent et al.'s (2017a) extension of the morphometric methods captures the presence and state of vegetation for aerodynamic parameter determination and wind-speed estimation. As green spaces become increasingly part of the urban fabric, understanding the implications of vegetation upon aerodynamic characteristics becomes more important. Further observations with different types, amounts and arrangements of vegetation will allow more thorough assessment of this parameterisation.

The methodology to determine $z_{d}$ and $z_{0}$ from surface elevation databases (including vegetation) is freely available in the Urban Multi-scale Environmental Predictor (UMEP, http://www.urban-climate.net/umep/UMEP) for the open source software QGIS. 
Acknowledgements SG's funding to support CWK (NERC CASE studentship in partnership with Risk Management Solutions, NE/L00853X/ 1) and the Newton Fund/Met Office CSSP China are gratefully acknowledged. Observations analysed are funded from Korean Meteorological Administration Research and Development Program (KMIPA20152063) (SFP) and NERC (SWD). JWH was supported by the Global Ph.D. Fellowship Program (NRF-2015H1A2A1030932). We thank Janet Barlow, Omduth Coceal, Sylvia Bohnenstengel, Duick Young and Marco Giometto for discussions regarding the morphometric parameterisation and analysis.

Open Access This article is distributed under the terms of the Creative Commons Attribution 4.0 International License (http:// creativecommons.org/licenses/by/4.0/), which permits use, duplication, adaptation, distribution and reproduction in any medium or format, as long as you give appropriate credit to the original author(s) and the source, provide a link to the Creative Commons license and indicate if changes were made.

\section{References}

Andersson-Sköld Y, Thorsson S, Rayner D, Lindberg F, Janhäll S, Jonsson A, Moback U, Bergman R, Granberg M (2015) An integrated method for assessing climate-related risks and adaptation alternatives in urban areas. Clim Risk Manage 7:31-50

Aubinet M, Grelle A, Ibrom A, Rannik U, Moncrieff J, Foken T, Kowalski AS, Martin PH, Berbigier P, Bernhofer C, Clement R (2000) Estimates of the annual net carbon and water exchange of forests: The EUROFLUX Methodology-X. Adv Ecol Res 30:113-175

Baldocchi D (1997) Flux footprints within and over forest canopies. Boundary-Layer Meteorol 85:273-292

Barlow JF, Coceal O (2009) A review of urban roughness sublayer turbulence. UK Met Office Technical Report no. 527, pp 68

Beljaars AC (1987) The measurement of gustiness at routine wind stations: a review. Roy Neth Meteorol Inst Sc Rep WR-87-11 (WMO Instr Meth Obs Rep 31)

Chang S, Huynh G (2007) A comparison of roughness parameters for Oklahoma City from different evaluation methods. AMS 7th Symposium on the Urban Environment 9.2. Available: https://ams. confex.com/ams/7Coastal7Urban/techprogram/paper_126674.htm

Cheng H, Castro IP (2002) Near wall flow over urban-like roughness. Boundary-Layer Meteorol 104:229-259

Choi T, Hong J, Kim J, Lee H, Asanuma J, Ishikawa H, Tsukamoto O, Zhiqiu G, Ma Y, Ueno K, Wang J (2004) Turbulent exchange of heat, water vapour, and momentum over a Tibetan prairie by eddy covariance and flux variance measurements. J Geophys Res Atmos 109:D21

Christen A (2005) Atmospheric turbulence and surface energy exchange in urban environments: results from the Basel Urban Boundary Layer Experiment (BUBBLE). Atmospheric turbulence and surface energy exchange in urban environments: results from the Basel Urban Boundary Layer Experiment (BUBBLE), Doctoral thesis, Department of Science, University of Basel, Switzerland

Coutts AM, White EC, Tapper NJ, Beringer J, Livesley SJ (2016) Temperature and human thermal comfort effects of street trees across three contrasting street canyon environments. Theo Appl Clim 124:55-68

Crawford B, Krayenhoff ES, Cordy P (2016) The urban energy balance of a lightweight low-rise neighborhood in Andacollo. Chile Theo Appl Clim Oct:1-14

Day SD, Eric Wiseman P, Dickinson SB, Roger Harris J (2010) Tree root ecology in the urban environment and implications for a sustainable rhizosphere. J Arboric 36:193
De Bruin HAR, Kohsiek W, Van Den Hurk BJJM (1993) A verification of some methods to determine the fluxes of momentum, sensible heat, and water vapour using standard deviation and structure parameter of scalar meteorological quantities. Boundary-Layer Meteorol 63: $231-257$

Feigenwinter C, Vogt R, Parlow E (1999) Vertical structure of selected turbulence characteristics above an urban canopy. Theo Appl Clim 62:51-63

Finnigan J (2000) Turbulence in plant canopies. Annu Rev Fluid Mech 32:519-571

Gill SE, Handley JF, Ennos AR, Pauleit S (2007) Adapting cities for climate change: the role of the green infrastructure. Built Environ 33:115-133

Giometto M, Christen A, Meneveau C, Fang J, Krafczyk M, Parlange M (2016) Spatial characteristics of roughness sublayer mean flow and turbulence over a realistic urban surface. Boundary-Layer Meteorol 160:425-452

Giometto MG, Christen A, Egli PE, Schmid MF, Tooke RT, Coops NC, Parlange MB (2017) Effects of trees on mean wind, turbulence and momentum exchange within and above a real urban environment. Adv Water Resour 106:154-168

Goodwin NR, Coops NC, Tooke TR, Christen A, Voogt JA (2009) Characterizing urban surface cover and structure with airborne lidar technology. Can J Remote Sens 35:297-309

Grant P, Nickling W (1998) Direct field measurement of wind drag on vegetation for application to windbreak design and modelling. Land Degrad Dev 9:57-66

Grimmond CSB, Blackett M, Best M, Baik J, Belcher S, Beringer J, Bohnenstengel S, Calmet I, Chen F, Coutts A (2011) Initial results from Phase 2 of the International Urban Energy Balance Model comparison. Int J Climatol 31:244-272

Grimmond CSB, Blackett M, Best M, Barlow J, Baik J, Belcher S, Bohnenstengel S, Calmet I, Chen F, Dandou A (2010) The international urban energy balance models comparison project: first results from phase 1. J Appl Meteorol Climatol 49:1268-1292

Grimmond CSB, King TS, Roth M, Oke TR (1998) Aerodynamic roughness of urban areas derived from wind observations. BoundaryLayer Meteorol 89:1-24

Grimmond CSB, Oke TR (1999) Aerodynamic properties of urban areas derived from analysis of surface form. J Appl Meteorol Climatol 38: $1262-1292$

Grimmond CSB, Salmond J, Offerle BD, Oke TR (2002) Local-scale surface flux measurements at a downtown site in Marseille during the ESCOMPTE field campaign. In: Proceedings, 4th Conference on Urban Environment, Norfolk, U.S.A., 20-24 May 2002, American Meteorological Society, 45 Beacon St., Boston, MA, pp $21-22$

Gromke C, Ruck B (2009) On the impact of trees on dispersion processes of traffic emissions in street canyons. Boundary-Layer Meteorol 131:19-34

Guan D, Zhu T, Han S (2000) Wind tunnel experiment of drag of isolated tree models in surface boundary layer. J For Res 11:156-160

Guan D, Zhang Y, Zhu T (2003) A wind-tunnel study of windbreak drag. Agric For Meteorol 118:75-84

Hagen L, Skidmore E (1971) Windbreak drag as influenced by porosity. Trans ASAE 14:464-0465

Hagishima A, Tanimoto J, Nagayama K, Meno S (2009) Aerodynamic parameters of regular arrays of rectangular blocks with various geometries. Boundary-Layer Meteorol 132:315-337

Hall D, Macdonald JR, Walker S, Spanton AM (1996) Measurements of dispersion within simulated urban arrays - a small scale wind tunnel study, BRE Client Report, CR178/96

Harman I, Finnigan J (2007) A simple unified theory for flow in the canopy and roughness sublayer. Boundary-Layer Meteorol 123: 339-363 
Heaviside C, Cai X, Vardoulakis S (2015) The effects of horizontal advection on the urban heat island in Birmingham and the West Midlands, United Kingdom during a heatwave. Q J R Meteorol Soc 141:1429-1441

Heidbach K, Schmid HP, Mauder M (2017) Experimental evaluation of flux footprint models. Agric For Meteorol 246:142-153

Heisler GM (1984) Measurements of solar radiation in the shade of individual trees. In: Hutchinson BA, Hicks BB (eds) The ForestAtmosphere interaction. Springer, Netherlands, pp 319-355

Heisler GM, Dewalle DR (1988) Effects of windbreak structure on wind flow. Agric Ecosyst Environ 22:41-69

Högström U (1996) Review of some basic characteristics of the atmospheric surface layer. Boundary-Layer Meteorol 28:215-246

Hong J, Kim J, Byun Y (2012) Uncertainty in carbon exchange modelling in a forest canopy due to $\mathrm{kB}-1$ parameterizations. Quart J Roy Meteor Soc 138:699-706

Hong J, Kwon H, Lim J, Byun Y, Lee J, Kim J (2009) Standardization of KoFlux eddy-covariance data processing. Korean J Agric For Meteorol 11:19-26

Hsieh C, Katul GG, Schieldge J, Sigmon J, Knoerr KR (1996) Estimation of momentum and heat fluxes using dissipation and flux-variance methods in the unstable surface layer. Water Resour Res 32:24532462

Jackson P (1981) On the displacement height in the logarithmic velocity profile. J Fluid Mech 111:15-25

Jiang D, Jiang W, Liu H, Sun J (2008) Systematic influence of different building spacing, height and layout on mean wind and turbulent characteristics within and over urban building arrays. Wind Struct 11:275-289

Kaimal JC, Finnigan JJ (1994) Atmospheric boundary layer flows: their structure and measurement. Oxford University Press, Oxford, 289 pp

Kanda M, Inagaki A, Miyamoto T, Gryschka M, Raasch S (2013) A new aerodynamic parametrization for real urban surfaces. BoundaryLayer Meteorol 148:357-377

Kanda M, Moriwaki R, Roth M, Oke TR (2002) Area-averaged sensible heat flux and a new method to determine zero-plane displacement length over an urban surface using scintillometry. Boundary-Layer Meteorol 105:177-193

Kastner-Klein P, Rotach MW (2004) Mean flow and turbulence characteristics in an urban roughness sublayer. Boundary-Layer Meteorol 111:55-84

Kent CW, Grimmond CSB, Gatey D (2017a) Aerodynamic roughness parameters in cities: Inclusion of vegetation. J Wind Eng Ind Aerodyn 169:168-176

Kent CW, Grimmond CSB, Barlow J, Gatey D, Kotthaus S, Lindberg F, Halios CH (2017b) Evaluation of Urban Local-Scale Aerodynamic Parameters: Implications for the Vertical Profile of Wind Speed and for Source Areas. Boundary-Layer Meteorol 164:183-213

Kljun N, Calanca P, Rotach M, Schmid H (2015) A simple twodimensional parameterisation for Flux Footprint Prediction (FFP). Geosci Model Dev 8:3695-3713

Koizumi A, Motoyama J, Sawata K, Sasaki Y, Hirai T (2010) Evaluation of drag coefficients of poplar-tree crowns by a field test method. J Wood Sci 56:189-193

Kormann R, Meixner FX (2001) An analytical footprint model for nonneutral stratification. Boundary-Layer Meteorol 99:207-224

Krayenhoff E, Santiago J, Martilli A, Christen A, Oke TR (2015) Parametrization of drag and turbulence for urban neighbourhoods with trees. Boundary-Layer Meteorol 156:157-189

Kremer P, Andersson E, McPhearson T, Elmqvist T (2015) Advancing the frontier of urban ecosystem services research. Ecosyst Serv 12: $149-151$

Kustas WP, Blanford JH, Stannard DI, Daughtry CS, Nichols WD, Weltz MA (1994) Local energy flux estimates for unstable conditions using variance data in semiarid rangelands. Water Resour Res 30: 1351-1361

Landry SM, Chakraborty J (2009) Street trees and equity: evaluating the spatial distribution of an urban amenity. Environ Plann A 41:26512670

Leclerc MY, Foken T (2014) Footprints in micrometeorology and ecology. Springer, Berlin, p 239

Lindberg F, Grimmond CSB (2011) Nature of vegetation and building morphology characteristics across a city: influence on shadow patterns and mean radiant temperatures in London. Urban Ecosyst 14: $617-634$

Lindberg F, Grimmond CSB, Gabey A, Huang B, Kent CW, Sun T, Theeuwes NE, Järvi L, Ward HC, Capel-Timms I, Chang Y, Jonsson P, Krave N, Liu D, Meyer D, Olofson KFG, Tan J, Wästberg D, Xue L, Zhang Z (2018) Urban Multi-scale Environmental Predictor (UMEP): An integrated tool for city-based climate services. Environ Model Softw 99:70-87

Liu G, Sun J, Jiang W (2009) Observational verification of urban surface roughness parameters derived from morphological models. Meteorol Appl 16:205-213

Macdonald R, Griffiths R, Hall D (1998) An improved method for the estimation of surface roughness of obstacle arrays. Atmos Environ 32:1857-1864

Mavrogianni A, Davies M, Taylor J, Chalabi Z, Biddulph P, Oikonomou E, Das P, Jones B (2014) The impact of occupancy patterns, occupant-controlled ventilation and shading on indoor overheating risk in domestic environments. Build Environ 78:183-198

Mayhead G (1973) Some drag coefficients for British forest trees derived from wind tunnel studies. Agric Meteorol 12:123-130

McMillen RT (1988) An eddy correlation technique with extended applicability to non-simple terrain. Boundary-Layer Meteorol 43:231245

Millward-Hopkins J, Tomlin A, Ma L, Ingham D, Pourkashanian M (2011) Estimating aerodynamic parameters of urban-like surfaces with heterogeneous building heights. Boundary-Layer Meteorol $141: 443-465$

Millward-Hopkins J, Tomlin A, Ma L, Ingham D, Pourkashanian M (2012) The predictability of above roof wind resource in the urban roughness sublayer. Wind Energy 15:225-243

Moncrieff JB, Massheder JM, De Bruin H, Elbers J, Friborg T, Heusinkveld B, Kabat P, Scott S, Soegaard H, Verhoef A (1997) A system to measure surface fluxes of momentum, sensible heat, water vapour and carbon dioxide. J Hydrol 188:589-611

Nakai T, Sumida A, Daikoku KI, Matsumoto K, van der Molen MK, Kodama Y, Kononov AV, Maximov TC, Dolman AJ, Yabuki H, Hara T (2008) Parameterisation of aerodynamic roughness over boreal, cool-and warm-temperate forests. Agric For Meteorol 148: 1916-1925

Owen PR, Thomson WR (1963) Heat transfer across rough surfaces. J Fluid Mech 15:321-334

Panofsky HA, Tennekes H, Lenschow DH, Wyngaard JC (1977) The characteristics of turbulent velocity components in the surface layer under convective conditions. Boundary-Layer Meteorol 11:355361

Papale D, Reichstein M, Canfora E, Aubinet M, Bernhofer C, Longdoz B, Kutsch W, Rambal S, Valentini R, Vesala T, Yakir D (2006) Towards a more harmonized processing of eddy covariance $\mathrm{CO} 2$ fluxes: algorithms and uncertainty estimation. Biogeosci Discuss 3:961-992

Rannik Ü, Aubinet M, Kurbanmuradov O, Sabelfeld KK, Markkanen T, Vesala T (2000) Footprint analysis for measurements over a heterogeneous forest. Boundary-Layer Meteorol 97:137-166

Raupach M (1992) Drag and drag partition on rough surfaces. BoundaryLayer Meteorol 60:375-395

Raupach M (1994) Simplified expressions for vegetation roughness length and zero-plane displacement as functions of canopy height and area index. Boundary-Layer Meteorol 71:211-216 
Rotach M (1994) Determination of the zero plane displacement in an urban environment. Boundary-Layer Meteorol 67:187-193

Roth M (2000) Review of atmospheric turbulence over cities. Q J R Meteorol Soc 126:941-990

Roth M, Oke TR (1995) Relative efficiencies of turbulent transfer of heat, mass, and momentum over a patchy urban surface. J Atmos Sci 52: 1863-1874

Roy S, Byrne J, Pickering C (2012) A systematic quantitative review of urban tree benefits, costs, and assessment methods across cities in different climatic zones. Urban For Urban Greening 11:351-363

Rudnicki M, Mitchell SJ, Novak MD (2004) Wind tunnel measurements of crown streamlining and drag relationships for three conifer species. Canadian J For Res 34:666-676

Salmond J, Williams D, Laing G, Kingham S, Dirks K, Longley I, Henshaw G (2013) The influence of vegetation on the horizontal and vertical distribution of pollutants in a street canyon. Sci Total Environ 443:287-298

Salmond JA, Tadaki M, Vardoulakis S, Arbuthnott K, Coutts A, Demuzere M, Dirks KN, Heaviside C, Lim S, Macintyre H (2016) Health and climate related ecosystem services provided by street trees in the urban environment. Environ Health 15:95

Schmid HP (1997) Experimental design for flux measurements: matching scales of observations and fluxes. Agric For Meteor 87:179-200

Schmid HP, Oke TR (1990) A model to estimate the source area contributing to turbulent exchange in the surface layer over patchy terrain. Q J R Meteorol Soc 116:965-988

Schubert S, Grossman-Clarke S, Martilli A (2012) A double-canyon radiation scheme for multi-layer urban canopy models. BoundaryLayer Meteorol 145:439-468

Shaw RH, Pereira AR (1982) Aerodynamic roughness of a plant canopy: a numerical experiment. Agric Meteorol 26:51-65

Simpson IJ, Thurtell GW, Neumann HH, Den Hartog G, Edwards GC (1998) The validity of similarity theory in the roughness sublayer above forests. Boundary-Layer Meteorol 87:69-99

Smith CL, Webb A, Levermore G, Lindley S, Beswick K (2011) Finescale spatial temperature patterns across a UK conurbation. Clim Chang 109:269-286

Sogachev A, Lloyd J (2004) Using a one-and-a-half order closure model of the atmospheric boundary layer for surface flux footprint estimation. Boundary-Layer Meteorol 112:467-502

Sorbjan Z (1989) Structure of the atmospheric boundary layer. Prentice Hall, Old Tappan, p 315

Stewart ID, Oke TR (2012) Local climate zones for urban temperature studies. Bull Am Meteorol Soc 93:1879-1900

Stovin V, Jorgensen A, Clayden A (2008) Street trees and stormwater management. Arboric J 30:297-310

Tallis M, Taylor G, Sinnett D, Freer-Smith P (2011) Estimating the removal of atmospheric particulate pollution by the urban tree canopy of London, under current and future environments. Landsc Urban Plan 103:129-138

Tanaka S, Sugawara H, Narita K, Yokoyama H, Misaka I, Matsushima D (2011) Zero-plane displacement height in a highly built-up area of Tokyo. Sola 7:93-96

Tennekes H (1973) The logarithmic wind profile. J Atmos Sci 30:234238

Thom AS, Stewart JB, Oliver HR, Gash JHC (1975) Comparison of aerodynamic and energy budget. Q J R Meteorol Soc 101:93-105

Tillman J (1972) The indirect determination of stability, heat and momentum fluxes in the atmospheric boundary layer from simple scalar variables during dry unstable conditions. J Appl Meteorol 11:783792

Tiwary A, Sinnett D, Peachey C, Chalabi Z, Vardoulakis S, Fletcher T, Leonardi G, Grundy C, Azapagic A, Hutchings TR (2009) An integrated tool to assess the role of new planting in PM 10 capture and the human health benefits: a case study in London. Environ Pollut $157: 2645-2653$
Toda M, Sugita M (2003) Single level turbulence measurements to determine roughness parameters of complex terrain. J Geophys Res Atmos 1984-2012:108

Tsuang B, Tsai J, Lin M, Chen C (2003) Determining aerodynamic roughness using tethersonde and heat flux measurements in an urban area over a complex terrain. Atmos Environ 37:1993-2003

Vesala T, Järvi L, Launiainen S, Sogachev A, Rannik Ü, Mammarella I, Siivola E, Keronen P, Rinne J, Riikonen ANU, Nikinmaa E (2008) Surface-atmosphere interactions over complex urban terrain in Helsinki, Finland. Tellus B 60:188-199

Vico G, Revelli R, Porporato A (2014) Ecohydrology of street trees: design and irrigation requirements for sustainable water use. Ecohydrology 7:508-523

Vollsinger S, Mitchell SJ, Byrne KE, Novak MD, Rudnicki M (2005) Wind tunnel measurements of crown streamlining and drag relationships for several hardwood species. Canadian J For Res 35:12381249

Voogt JA, Grimmond CSB (2000) Modeling surface sensible heat flux using surface radiative temperatures in a simple urban area. J Appl Meteorol 39:1679-1699

Vos PE, Maiheu B, Vankerkom J, Janssen S (2013) Improving local air quality in cities: to tree or not to tree? Environ Pollut 183:113-122

Ward HC, Evans JG, Grimmond CSB (2013) Multi-season eddy covariance observations of energy, water and carbon fluxes over a suburban area in Swindon, UK. Atmos Chem Phys 13:4645-4666

Ward HC, Evans JG, Grimmond CSB (2014) Multi-scale sensible heat fluxes in the suburban environment from large-aperture scintillometry and eddy covariance. Boundary-Layer Meteorol 152:65-89

Ward HC, Evans JG, Grimmond CSB (2015c) Infrared and millimetrewave scintillometry in the suburban environment-Part 2: Large-area sensible and latent heat fluxes. Atmos Meas Tech 8:1407-1424

Ward HC, Evans JG, Grimmond CSB, Bradford J (2015b) Infrared and millimetre-wave scintillometry in the suburban environment-Part 1: Structure parameters. Atmos Meas Tech 8:1385-1405

Ward HC, Grimmond CSB (2017) Assessing the impact of changes in surface cover, human behaviour and climate on energy partitioning across Greater London. Landsc Urban Plan 165:142-161

Ward HC, Kotthaus S, Grimmond CSB, Bjorkegren A, Wilkinson M, Morrison WTJ, Evans JG, Morison JIL, Iamarino M (2015a) Effects of urban density on carbon dioxide exchanges: Observations of dense urban, suburban and woodland areas of southern England. Environ Pollut 198:186-200

Ward HC, Kotthaus S, Järvi L, Grimmond CSB (2016) Surface Urban Energy and Water Balance Scheme (SUEWS): development and evaluation at two UK sites. Urban Clim 18:1-32

Willmott CJ, Matsuura K (2005) Advantages of the mean absolute error (MAE) over the root mean square error (RMSE) in assessing average model performance. Clim Res 30:79-82

Wolfe SA, Nickling WG (1993) The protective role of sparse vegetation in wind erosion. Prog Phys Geogr 17:50-50

Wyngaard J, Coté O, Izumi Y (1971) Local free convection, similarity, and the budgets of shear stress and heat flux. J Atmos Sci 28:11711182

Xie Z, Coceal O, Castro IP (2008) Large-eddy simulation of flows over random urban-like obstacles. Boundary-Layer Meteorol 129:1-23

Zaki SA, Hagishima A, Tanimoto J, Ikegaya N (2011) Aerodynamic parameters of urban building arrays with random geometries. Boundary-Layer Meteorol 138:99-120

Zilitinkevich SS (1995) Non-local turbulent transport: pollution dispersion aspects of coherent structure of convective flows. In: Power $\mathrm{H}$, Moussiopoulos N, Brebbia CA (eds) Air Pollution, Volume I. Air Pollution Theory and Simulation. Computational Mechanics Publications, Boston, pp 53-60 